\title{
Synthesis of high added value molecules with MOF catalysts
}

\author{
Nuria Martín ${ }^{a}$ and Francisco G. Cirujano*a
}

Received 00th January 20xx, Accepted 00th January 20xx

Recent examples of organic synthesis of fine chemicals and pharmaceuticals in confined spaces of MOFs are highlighted and compared with silica-based ordered porous solids, such as zeolites or mesoporous (organo)silica. These heterogeneous catalysts offer the possibility to stabilize the desired transition states and/or intermediates during organic transformations of functional groups and (C-C/C-N) bond forming steps towards the desired functional high added value molecular scaffolds. A short introduction on zeolites, mesoporous silica and metal-organic frameworks is followed by relevant applications in which confined active sites in the pores promote single or multi-step organic synthesis of industrially relevant molecules. A critical discussion on the catalytic performance of the different type of hybrid inorganic-organic catalysts in the synthesis of $\mathrm{O}$ - and $\mathrm{N}$-containing acyclic and heterocyclic molecules has been tackled, based on experimental or ab initio quantitative kinetic data

\section{Ordered porous solids as confined spaces for organic synthesis: MOFs as catalysts}

The synthesis of complex molecules of industrial relevance, such as fine chemicals or pharmaceuticals, is based on organic synthetic methodology that employs multiple reagents and catalysts. To achieve the active and selective control of the reactants pathway towards the reaction products, important breakthroughs on homogeneous catalysed synthetic steps have been made over the last two decades.1,2 However, the contamination of the reaction products is, beside cost and toxicity, often the major problem with soluble (usually precious metal) catalysts. Moreover, these reaction promotors often suffer from deactivation/degradation (decreasing the number of turnovers or productivity), moderate selectivity (towards the activation of the desired functional group) and complicated product purification (from the high added value organic molecules). ${ }^{3}$ This highlights the need for advanced catalysts with the appropriate design, reactivity and long term stability to be applied in diverse organic synthesis steps.

The concept of heterogeneous catalysis clearly offers, in the ideal case, a simpler recovery of the reaction product (from the solid catalyst) in a liquid media, which can be recycled by filtration or centrifugation, minimizing the contamination of the targeted synthetic product. ${ }^{4,5}$ Furthermore, such reactive solid could be employed during longer reaction times under broader reaction conditions, working with a continuous flow of

\section{a Instituto de Ciencia Molecular (ICMol)}

Universitat de Valencia

Catedrático José Beltrán Martínez no 2, 46980 Paterna, Valencia, Spain

E-mail: francisco.c.garcia@uv.es

† Footnotes relating to the title and/or authors should appear here.

Electronic Supplementary Information (ESI) available: [details of any supplementary information available should be included here]. See DOI: 10.1039/x0xx00000x reactants to separate the product without leaving the reactor environment, offering simple scale-up, step-economy, high yields, safety and reproducibility. ${ }^{6-11}$ Among the different solids employed as heterogeneous catalysts (e.g. amorphous carbon, polymers, crystalline metal oxides, etc.) ordered porous solids are the most appealing from the point of view of fundamental understanding and control of the chemical transformation in the pores (which are of the same dimension, shape and functionality throughout the crystal).

Figure 1. Ordered Porous Solids with confined spaces in the nano-regime.

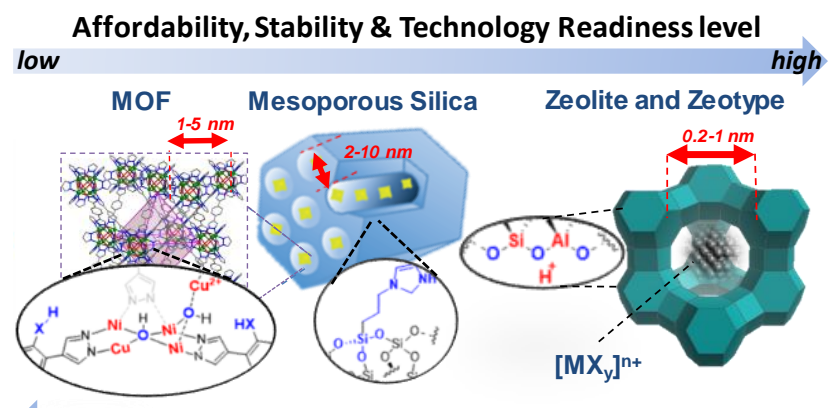

Level of functionality, porosity and flexibility control

The rational design of well-isolated/dispersed active sites, controlling its steric and electronic environment in confined spaces of ordered porous solids (e.g. pores of 0.5-10 nm), could (in principle) tackle challenging "enzyme-like" tasks such as: (i) molecular transport and recognition of reactants at tunable binding sites; (ii) hosting labile organometallic species to increase its stability; (iii) chemical functionalization of the reactants during the synthetic steps. Traditionally, confined spaces in ordered porous hybrid organic-inorganic silica-based 3D-frameworks have been widely employed in a vast amount of organic synthetic steps. ${ }^{12,13}$ In the recent years, a versatile class 
of coordination polymers with permanent porosity, known as Metal-Organic Frameworks (MOFs), have shown a great deal of interest as next generation catalysts in liquid media under mild conditions. ${ }^{14,} 20$

Herein we focus on three main ordered porous solid platforms for tailoring the confined space (i.e. geometry and composition) where the organic transformation takes place: zeolites, mesoporous (organo)silica and MOFs (see Figure 1). On the one side of the spectrum, there are zeolites as well-established catalysts, industrially produced at low cost and offering a high stability. On the other side, MOFs have appeared as new materials with high potential in adsorption and catalysis, but with very limited industrial applications due to their high cost and lability. We aim to show the strengths and limitations of this new type of porous solids, in the context of a sustainable organic synthesis. The contextualization of MOFs with respect to aluminosilicates as heterogeneous catalysts in organic synthesis has been previously revised. ${ }^{4}, 21-23$ This minireview summarizes most of the work carried out during the decade 2010-2020 in the design of MOFs as multifunctional catalysts for organic synthesis of high added value compounds, in contrast to the well-established and less tunable aluminosilcates. The focus will be on its versatility and optimal performance in the synthesis of pharmaceutically interesting scaffolds.

\subsection{Zeolites}

Zeolites are, generally, very stable (mechanically, thermally and chemically) crystalline aluminosilicates, having pores of different (and tunable) shapes and sizes, which allow for molecular selectivity either by selecting the reagent, the product or the transition state. They have been studied as heterogeneous catalysts in organic transformations of fine chemicals during the last decades of the XX century. ${ }^{24,25}$ At the beginning of this century, Climent et al. reviewed the state-ofthe-art of solid acid catalysts for the broad field of fine chemicals. ${ }^{26}$ Recently, the Pale group gave a leap forward by reporting the first Zeolite-Based Organic Synthesis (ZeoBOS) of complex organic compounds, such as the total synthesis of acortatarin A. ${ }^{27}$ On the one hand, zeolites can be used in their native form with their acidic aluminosilicate framework as a solid Brønsted acid. On the other hand, transition metal-doped zeolites incorporate Lewis acid sites depending on the nature of the metal ions loaded into the zeolite (extraframework) pores or tetrahedral framework sites. However, it is difficult to introduce a broad spectrum of metals due to the restricted coordination environment of the tetrahedrally coordinated silicate frameworks. Moreover, the enlargement of the pore size in zeolites is not straightforward and cannot simply be controlled, requiring challenging synthetic conditions. The most employed zeolite platforms are those with large pores, e.g. ultrastable Y (USY) or zeolite beta (BEA), due to their large pore diameters $(\sim 0.7 \mathrm{~nm})$, which are able to accommodate several molecules together in the inner pores (Figure 2, left). Furthermore, these zeolites are produced using available silicon/aluminum sources in a water media, using relatively inexpensive inorganic and/or organic structure directing agents.
This simplify the upscaling of these crystalline porous solids for the industrial upgrading of petrochemicals and fine chemicals.

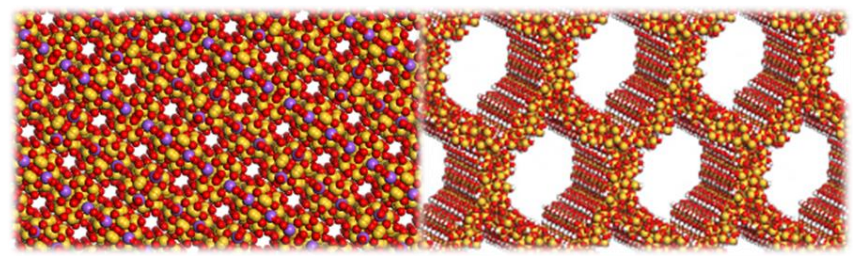

Figure 2. Silicate-based ordered porous solids: FAU large pore $(0.7 \mathrm{~nm})$ microporous zeolite (left), MCM-41 mesoporous (2-3 $\mathrm{nm}$ ) silica (right).

\subsection{Mesoporous Silica}

Tailored functionalized periodic (ordered) mesoporous organosilica offers higher tunability with respect to zeolites, at expense of the use of relatively costly surfactant structure directing agents. Despite their lower crystallinity and stability with respect to zeolites, it is possible to introduce a different type of active sites (metallic, organic or metal-organic) embedded at confined spaces by co-condensation of different organosilane precursors, solid-state crystallization of metaloxide or metal-organic nanoparticles.4, 13, 28, 29 Being not as stable as crystalline microporous zeolites, they can offer a higher mechanical, chemical and thermal stability under broader conditions, as well as easy synthesis and low cost with respect to many high surface area metal-organic polymers. As happens in most of the porous solids reviewed here, sol-gel syntheses enable full control over the porosity and site isolation due to the structural rigidity. Most importantly, these mesoporous solids possess large-tunable pore size/channels, ensuring confinement of large molecules, typically employed in the fine chemical and pharmaceutical industries (see Figure 2, right). Finally, they allow the simple immobilization of homogeneous (chiral) organocatalysts by covalent grafting, presenting higher stability and minimizing its leaching under mild reaction conditions.

Among the multiple mesoporous silicas described so far, two of the most employed are MCM-41 and SBA-15. ${ }^{30,31}$ They possess high surface areas $\left(800-1400 \mathrm{~m}^{2} \cdot \mathrm{g}^{-1}\right)$ and tunable pore dimensions (2-50 $\mathrm{nm})$, which enable catalytic reactions involving bulky substrates and/or products. However, in contrast to the crystalline nature of zeolites and MOFs, mesoporous silica exhibit amorphous walls, which limits their rational design and catalytic performance of the embedded active sites. Thus, the development of crystalline materials with ordered mesopores (in addition to the possible presence of intrinsic microporosity, i.e. hierarchical material) is at the forefront of research in porous solids. The rich reticular chemistry of metal-organic frameworks is key in such endeavor, where there is a plethora of secondary building units.

\subsection{Metal-Organic Frameworks}

Metal-Organic Frameworks (MOFs) are versatile and tunable porous materials with crystalline structures generated upon coordination of metal ions to polytopic organic linkers. In this class of multifunctional hybrid organic-inorganic materials, the 
active sites are strongly bonded and isolated either at the inorganic nodes, organic linkers or porous architectures. ${ }^{14-23,32}$ MOFs present an important advancement with respect to traditional catalysts (i.e. zeolites, carbon or crosslinked polymers) since they offer a much higher activity than homogeneous catalysts due to site isolation, avoiding their selfdeactivation, and positional or stereo-selectivity through spatial confinement. Their large and tunable pore diameters ( 1-5 $\mathrm{nm}$ ) and high surface areas ensure an adequate diffusion through the pores, in contrast to other microporous inorganic solids or organic polymers. Moreover, strong metal-ligand bonds keep the active sites fixed in the structure, which decrease its leaching during the catalysis.

Metal-organic frameworks (MOFs) offer great opportunities for the rational design of ordered porous solids, exhibiting high flexibility (metal-organic enzyme-like features) in contrast with rigid less functional silica supports. ${ }^{33-35}$ The crystalline nature of the MOF allows the fine-tuning of the host-guest interactions and chemical reactivity through the precise three-dimensional control of the geometry and functionality of the micro-/mesopores at atomic level, enabling a predictable catalytic performance and a fundamental characterization of the active sites. In particular, the coordination environments of metalligand sites can be defined under certain synthetic conditions.

Figure 3. Examples of MOFs with different SBUs: a) $\mathrm{Zn}_{4} \mathrm{O}$ in
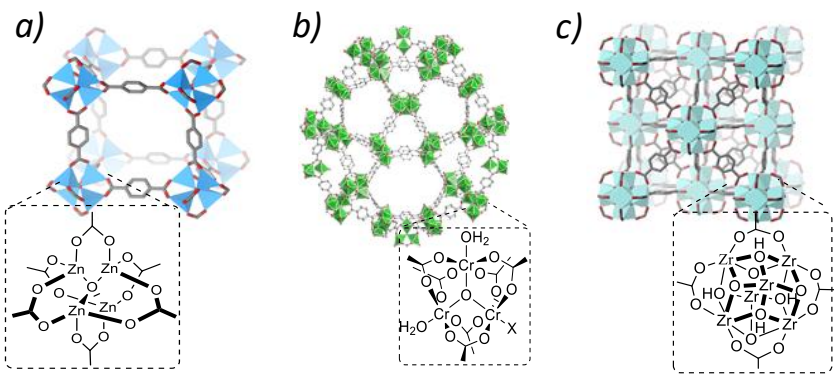

$\mathrm{Zn}(\mathrm{II}) \mathrm{MOF}-5, \mathrm{~b}) \mathrm{Cr}_{3} \mathrm{O}$ in $\mathrm{Cr}(\mathrm{III}) \mathrm{MIL}-101$ y c) $\mathrm{Zr}_{6} \mathrm{O}_{8}$ in $\mathrm{Zr}(\mathrm{IV}) \mathrm{UiO}-66$

For example, for the common BDC (benzene-1,4-dicarboxylate) linker, different secondary building units (SBUs) can be obtained, with the corresponding framework topologies. In the case of $\mathrm{Zn}(\mathrm{II})$, the cubic structure of MOF-5 is formed from $\left[\mathrm{Zn}_{4} \mathrm{O}\right]^{6+}$ nodes as SBUs connected to BDC through carboxylate bridges at the edges of the cube, resulting in an extended $3 \mathrm{D}$ system with cubic cavities of $12.9 \AA$ between two adjacent SBUs and $8 \AA$ pore windows (Figure $3 a$ ). ${ }^{36}$ In the presence of $\mathrm{Cr}$ (III) or $\mathrm{Zr}(\mathrm{IV})$, the same BDC organic ions have been reported to form porous frameworks with inorganic $\left[\mathrm{Cr}_{3}\left(\mu_{3}-\mathrm{O}\right)(\mathrm{OH})\left(\mathrm{H}_{2} \mathrm{O}\right)_{2}\right]^{6+}$ trimers or $\left[\mathrm{Zr}_{6}\left(\mu_{3}-\mathrm{O}\right)_{4}\left(\mu_{3}-\mathrm{OH}\right)_{4}\right]^{12+}$ hexamers SBUs, resulting in MIL-101 and UiO-66 structures, respectively. The MIL-101 crystalline framework poses mesoporous cavities of $3 \mathrm{~nm}$ accessible through $1.5 \mathrm{~nm}$ windows (Figure $3 \mathrm{~b}$ ), ${ }^{37}$ while UiO-66 has $1 \mathrm{~nm}$ cavities accessible through $0.6 \mathrm{~nm}$ windows (Figure 3c). ${ }^{38}$

The pores of such terephthalate frameworks can be extended and/or functionalized in an isoreticular manner. By designing the appropriate linker and/or partially disconnecting some metal-linker bonds from the SBUs of the framework, one can increase the pore size and decorate the pore with the appropriate active sites. Beside the above mentioned carboxylate-type MOFs, azolate-based reticular materials have proven a high stability when using soft Lewis acid sites as building blocks, together with the possibility of linker extension. Table 1 summarizes the main MOFs reviewed here as heterogeneous catalysts, i.e. MOF-5, ${ }^{36}$ MIL-101,37 UiO-66, ${ }^{38}$ MOF-808, ${ }^{39}$ MOF-74, 40 and NiBDP, 41 in the context of traditional silicate-based porous solids.

Table 1. Composition and pore size of the ordered porous solids discussed.

\begin{tabular}{ccc}
\hline Name & Composition ${ }^{[a]}$ & $\mathrm{d}_{\text {pore }} / \mathrm{nm}$ \\
\hline MOF-5 & $\mathrm{Zn}_{4} \mathrm{O}(\mathrm{BDC})_{3}$ & $1.3 \mathrm{~nm}$ \\
MIL-101 & $\mathrm{Cr}_{3} \mathrm{O}(\mathrm{OH})\left(\mathrm{H}_{2} \mathrm{O}\right)_{2}(\mathrm{BDC})_{3}$ & $1.8-2.3 \mathrm{~nm}$ \\
UiO-66 & $\mathrm{Zr}_{6} \mathrm{O}_{4}(\mathrm{OH})_{4}(\mathrm{BDC})_{6}$ & $0.6 \mathrm{~nm}$ \\
MOF-808 & $\mathrm{Zr}_{6} \mathrm{O}_{5}(\mathrm{OH})_{3}(\mathrm{BTC})_{2}(\mathrm{Ac})_{5}$ & $1.4 \mathrm{~nm}$ \\
MOF-74 & $\mathrm{Zn}_{2}\left(\mathrm{DHBDC}_{(\mathrm{DMF})_{2}\left(\mathrm{H}_{2} \mathrm{O}\right)_{2}}\right.$ & $1.2 \mathrm{~nm}$ \\
NiBDP & $\mathrm{Ni}_{8}(\mathrm{OH})_{6}(\mathrm{BDP})_{6}$ & $1.6 \mathrm{~nm}$ \\
BEA & $\left(\mathrm{SiO}_{2}\right)_{\mathrm{m}}\left(\mathrm{Al}_{2} \mathrm{O}_{3}\right)_{\mathrm{n}}[[\mathrm{b}]$ & $0.7 \mathrm{~nm}$ \\
FAU $(\mathrm{USY})$ & $\left(\mathrm{SiO}_{2}\right)_{\mathrm{m}}\left(\mathrm{Al}_{2} \mathrm{O}_{3}\right)_{\mathrm{n}}$ & $0.7 \mathrm{~nm}$ \\
MCM-41 & $\mathrm{SiO}_{2}$ & $1-10 \mathrm{~nm}$ \\
SBA-15 & $\mathrm{SiO}_{2}$ & $5-30 \mathrm{~nm}$ \\
\hline
\end{tabular}

[a] $\mathrm{H}_{2} \mathrm{BDC}=1,4-$ benzene dicarboxylic acid; $\mathrm{H}_{3} \mathrm{BTC}=1,3,5-$ benzenetricarboxylic acid; $\mathrm{HAC}=$ acetic acid; $\mathrm{H}_{2} \mathrm{DHBDC}=2,5$ dihydroxiterephthalyc acid; $\mathrm{BDP}=1,4$-bis(pyrazol-4-yl)benzene. [b] $\mathrm{m} / 2 \mathrm{n}$ is the Si/Al ratio of the zeolite.

\section{Synthesis of $\boldsymbol{O}$-containing molecules: alcohols, carboxylic acids and esters}

Acid catalysed transformations (e.g. cyclizations, isomerizations, condensations, dehydrations, etc.) of oxygen containing molecules (e.g. alcohols, aldehydes, acids, etc.) have been widely studied under confinement in porous solid acids such as MOFs (e.g. Zr-UiO-66, Zr-MOF-808, Cr-MIL-101) and silicas (e.g. Zr-BEA, Sn-BEA). ${ }^{22}$ In this sense, the in-framework incorporation of heteroatoms with strong acid character, such as those with high charge and small size (e.g. $\mathrm{Al}^{3+}, \mathrm{Cr}^{3+}, \mathrm{Zr}^{+4}$, $\mathrm{Sn}^{+4}$ ), increases the catalytic activity of the porous solid. Here we focus mainly on (but not limited to) the Zr-MOF UiO-66, with a face centred close cubic packing of $\mathrm{Zr}_{6}$ octahedral clusters $\left[\mathrm{Zr}_{6} \mathrm{O}_{4}(\mathrm{OH})_{4}\right]^{12+}$, as secondary building units (SBUs), connected by twelve negatively charged terephthalate linkers. [38] However, some of the linkers (and/or clusters) may be missed 
from the structure, leaving exposed $\mathrm{Zr}$-Lewis or $\mathrm{Zr}\left(\mathrm{OH}_{2}\right)_{\mathrm{n}}$ Brønsted acid sites. ${ }^{42}$ One particular example that has been well-understood by both experimental and computational studies is the amino-functionalized isoreticular $\mathrm{UiO}-66-\mathrm{NH}_{2}$. This MOF acts as a dual acid-base catalyst, where the sites are in close proximity (2-3 $\AA$ ), showing high performance in the synthesis of industrially relevant $\alpha, \beta$-unsaturated aldehydes or biomass derived esters. ${ }^{43}, 44$ The carbonyl group of one of the substrates is activated on $\mathrm{Zr}$ sites located at defect positions and the acid hydrogen of the other at the amino groups of the ligand or $\mu_{3}$-oxygen atoms adjacent to $\mathrm{Zr}$. In this first part of the review, we will focus on several acid, acid-base or acid-redox catalysed organic transformations of carbonyl-containing molecules derived from biomass.
Similar active sites were proposed in the pores of zeolites, where protonated water clusters form if there are more than two water molecules, which then acts as a mobile active Brønsted acid site for the cyclohexanol dehydration. ${ }^{49}$

\subsection{Esters of biomass-derived carboxylic acids and alcohols: Addition-Elimination reactions}

Levulinic acid (3) is a valuable intermediate in the fine chemical industry of fragrances, flavours and plasticizers (see Scheme 1). ${ }^{22,} 50$ The $\mathrm{Zr}$-MOF UiO-66- $\mathrm{NH}_{2}$ with $8 \%$ of linker deficiency is able to promote the esterification of levulinic acid with ethanol (step b of Scheme 1) generating 230 molecules of the ester $4 \mathrm{~b}$ per zirconium atom associated to defects, in just one hour (TOF $\left.=230 \mathrm{~h}^{-1}\right)$. Indeed, UiO-66- $\mathrm{NH}_{2}$ samples with low linker deficiency, show lower catalytic activity. For UiO-66, the calculated kinetic rate constants varied between $0.07 \mathrm{~h}^{-1}$ and<smiles>[R7]OC(=O)CCC(C)=O</smiles>

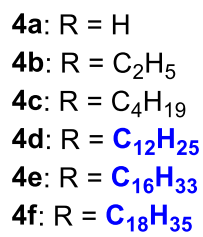

Scheme 1. Synthesis of hexose (fructose 1) derived fine chemicals (5-hydroxymethylfurfural 2, levulinic acid 3, alkyl levulinates 4 and $\gamma$-valerolactone $\mathbf{5}$ ).

\subsection{Olefins from dehydration of alcohols: Elimination reactions}

Olefins are important precursors in the chemical industry, thus, its production from available alcohols, e.g. methanol, is a current trend in the chemical industry. ${ }^{45}$ Zeolites with small pores in their structure become an attractive acid catalyst for the dehydration and coupling of methanol-derived intermediates at temperatures higher than $300^{\circ} \mathrm{C} .{ }^{46}$ However, the thermal instability of MOFs at such high temperatures/pressures limit its use for this type of $\mathrm{C} 1$ substrates and gas-to-liquid processes. Beside light MTOderived olefins, larger olefins such as isobutylene, are important intermediates in amination, alcoholysis, alkylation or polymerization steps. This olefin can be obtained by acid catalysed dehydration of t-butyl alcohol $(6.1 \times 6.7 \times 5.7 \AA)$ inside the pores of MOF-808 $(1.4 \mathrm{~nm}) .47$ The initial activity of MOF-808 was 100 times higher than UiO-66. On the one hand, MOF-808 has a higher amount and stronger Lewis acid sites than UiO-66, resulting in 6 times more vacancy sites per $\mathrm{Zr}_{6} \mathrm{O}_{8}$ node. ${ }^{48}$ On the other hand, MOF-808 has a larger pore aperture diameter than UiO-66 $(0.6 \mathrm{~nm})$, resulting in a rapid transport of the alcohol molecules in MOF-808. However, similar $\Delta \mathrm{G}^{\neq} \sim 150 \mathrm{~kJ} \cdot \mathrm{mol}^{-1}$ were calculated for the transition state, consisting on the concerted breaking of the $\mathrm{C}-\mathrm{O}$ and $\mathrm{C}-\mathrm{H}$ bonds of the alcohol, in both Zr-MOFs. In contrast to the unimolecular E1 mechanism established in vapour-phase dehydrations, a bimolecular E2 mechanism with the concerted $\mathrm{C}-\mathrm{O} / \mathrm{C}-\mathrm{H}$ bond scissions becomes the major dehydration route in this case. Furthermore, in UiO-66, the reaction rate per node can be increased up to $4.3 \mathrm{~h}^{-1}$ (6-fold higher than that of initial UiO-66) upon methanol and water steam treatment to generate $\mathrm{Zr}-\mathrm{OH}$ Brønsted acid sites, in addition to the cus $\mathrm{Zr}$ Lewis acid sites.
$0.61 \mathrm{~h}^{-1}$, an almost 9-fold increase from the less active $(2.5 \%$ linker deficiency) to the most active (13.2\% linker deficiency) material. However, for the same defect content, the amino functionalized MOF is more active than the parent UiO-66, suggesting the positive effect of the amino groups of the linker in the reaction mechanism.

The stronger adsorption of the alcohol and acid reactants on the UiO-66- $\mathrm{NH}_{2}$ stabilizes intermediates, transition states and products. The calculated $\Delta G^{\neq}$of the transition state corresponding to the bond breaking between the carbonyl carbon and the oxygen of the leaving group, lowers from 30.6 to $26.9 \mathrm{~kJ} \cdot \mathrm{mol}^{-1}$ for UiO-66 and UiO-66- $\mathrm{NH}_{2}$, respectively. ${ }^{44} \mathrm{~A}$ similar behaviour is observed for the dehydration of fructose into 5-hydroxymethylfurfural (see step a in Scheme 1), where the $\mathrm{NH}_{2} / \mathrm{NO}_{2}$ ratio in mix-linker UiO-66- $\mathrm{NH}_{2} / \mathrm{NO}_{2}$ samples increases the accessibility and activity of the defective $\mathrm{Zr}$ active sites. The sites present in the porous architecture of the UiO-66$\mathrm{NH}_{2}$ sample are able to produce 25 molecules of HMF (2) per defective $\mathrm{Zr}$ site $\left(\mathrm{TON}_{\mathrm{ZrOH}}=25\right) .{ }^{51}$ As described for the dehydration of alcohols, the anhydrous thermally treated $\mathrm{Zr}$ MOFs contain only Lewis acid sites, inactive or barely active in the dehydration of fructose. ${ }^{42}$ In a similar manner, (AI)-SBA-15 ( $\mathrm{Si}: \mathrm{Al}=40)$ mesoporous aluminosilicate was an active and selective catalyst in the dehydration of fructose to $\mathrm{HMF}$ $\left(\mathrm{TON}_{\mathrm{AlOH}}>100\right)$. In contrast, zeolites with strong acidity and narrower pores favour the strong adsorption and oligomerization of HMF in the zeolitic channels. ${ }^{52}$ 
$\mathrm{V}$-valerolactone (GVL, compound $\mathbf{5}$ in Scheme 1) is a non-toxic alternative to common polar aprotic solvents, such as $\mathrm{N}, \mathrm{N}$ dimethylformamide (DMF), dimethylacetamide, and N-methyl2-pyrrolidone, which are commonly used in cross-coupling reactions, with reduced metal leaching. ${ }^{53}$ An alternative to the use of hydrogen gas or formic acid in the synthesis of GVL consists of a chemoselective reduction of the keto group of LA by hydrogen transfer from a secondary alcohol as hydrogen source (step c in Scheme 1). MOF-808 has acid-base sites in the metal clusters $\left(\mathrm{Zr}^{4+}\right.$ and $\left.\mathrm{O}^{2-}\right)$ that interact with both isopropanol and ethyl levulinate to form a six membered ring transition state. This results in 7 molecules of GVL per atom of $\mathrm{Zr}$ in the MOF-808 (TOF $\left.=7 \mathrm{~h}^{-1}\right) .{ }^{54}$ However, the $\mathrm{Zr}$ Lewis acid sites in the zeolite Zr-Beta (with high Si/Al ratio or low Brønsted acidity) surpass the activity and stability of MOFs in this particular case, exhibiting TOF values one order of magnitude higher (TOF $=90$ $\left.\mathrm{h}^{-1}\right) .55,56$

Lactones are important intermediates or final products in the fine chemical and pharmaceutical industries. Beside the above mentioned 5-membered-ring GVL (5), the synthesis of 6membered-ring lactones such as coumarins using MOFs has been recently reported. ${ }^{57}$ The synthesis proceeds through the cyclization of ethyl acetoacetate and resorcinol, in the presence of sulfamic acid containing $\mathrm{Cu}_{2}(\mathrm{BTC})_{3}$ (HKUST-1). Moreover, coumarins with different benzylic $\mathrm{Csp}^{3}-\mathrm{H}$ bonds have been used as substrates in cross-dehydrogenative couplings, catalysed by iron or copper MOFs under oxidant and basic conditions. ${ }^{58}$ Other interesting application of MOFs are as support of active carbonylation catalysts, as in the case of $\mathrm{Co}(\mathrm{CO})_{4} @ \mathrm{MIL}-101$. This heterogeneous system allows for the practical synthesis of $\beta$ lactones through the carbonylation of epoxides. ${ }^{59}$ Moreover, the resulting lactone can be used in a subsequent carbonylation towards industrially relevant succinic anhydrides (1300 $\mathrm{mol}_{\text {Anhydride }} \cdot \mathrm{mol}_{\mathrm{Co}^{-1}}$ over $6 \mathrm{~h}$ on stream). 60
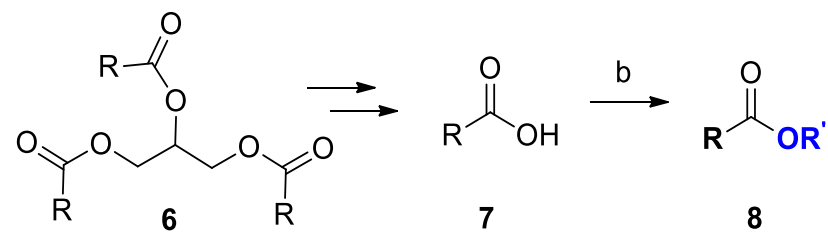

Scheme 2. Synthesis of triglyceride derived fine chemicals (free fatty acids $\mathbf{7}$ and free fatty acid esters $\mathbf{8}$ ) with different type of alkyl chain from the acid or alcohol (8a-f).

UiO-66 has been employed for the esterification of levulinic acid with larger alcohols resulting in 15 molecules of long-chain alkyl levulinate esters (4d-f) per zirconium atoms associated to defects, in just one hour. ${ }^{50}$ The hindered diffusion of the bulky alcohols to the narrow UiO pores $(0.7 \mathrm{~nm})$ is the reason of the lower activity with respect to the use of ethanol (TOF = $15 \mathrm{vs}$. $117 \mathrm{~h}^{-1}$ ), where both $\mathrm{Zr}$ sites located at the inner and external surface of the MOF particles participate in the reaction. Beside alcohols, the influence of the carboxylic acid substrate was studied aiming at the production of fatty acid esters using UiO66 nanocrystals (see product 8 in Scheme 2). ${ }^{61}$ Both long alkyl chains and the presence of unsaturations decreases the esterification reaction rate constant respect to smaller levulinic

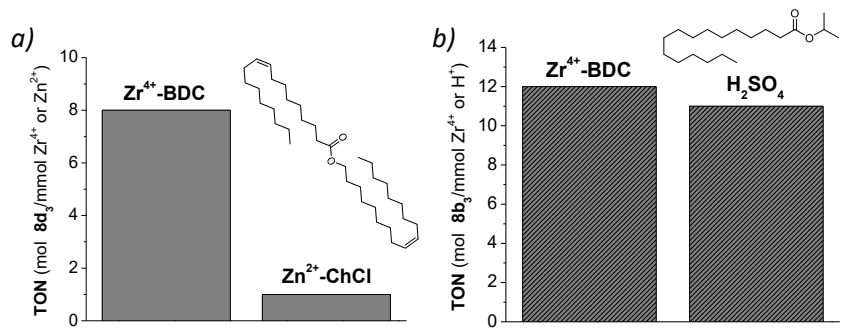

Figure 4. Performance of UiO-66 ( $\left.\mathrm{Zr}^{4+-} \mathrm{BDC}\right)$ with respect to $\mathrm{Zn}^{2+-}$ choline chloride (a) or sulphuric acid (b) in esterification reactions of free fatty acids.

acid. The MOF outperforms ionic liquids and mineral acids producing 8 molecules of the oleyl oleate "jojoba" oil analogue and up to 12 molecules of isopropyl palmitate per $\mathrm{Zr}$ site, employed in cosmetics and as industrial lubricant (see Figure 4).

\subsection{Carbonyl activations in Steroids: esterification and selective reduction of $\alpha, \beta$-unsaturated ketones}

The selective transformation of terpene-like substrates using hydrogenating metals on zeolites (i.e. BEA) or mesoporous silica (i.e. MCM-41) has been studied in detail by the groups of Coman and De Vos. On the one hand, Pt/Sn/MCM-41 or Ru/BEA were employed in the diastereoselective hydrogenation of a prostaglandin intermediate enone to secondary allylic alcohols. 62,63 On the other hand, Ir/BEA zeolite was successfully employed in the selective hydrogenation of steroidal enones into the corresponding alcohol.[64] Inspired by this pioneering works, testosterone and epiandrosterone were selectively transformed using $\mathrm{Zr}$-containing MOF nanocrystals (ca. $5 \mathrm{~nm}$ ) confined in the monodimensional channels $(9 \mathrm{~nm})$ of mesoporous silica (SBA-15). ${ }^{65}$

$$
\begin{aligned}
& \mathrm{R}=\mathrm{C}_{12} \mathrm{H}_{23} ; \mathbf{8} \mathrm{a}_{1}: \mathrm{R}^{\prime}=\mathrm{CH}_{3} ; \mathbf{8} \mathrm{a}_{\mathbf{2}}: \mathrm{R}^{\prime}=\mathrm{CH}_{3} \mathrm{C}_{2} \mathrm{H}_{5} \\
& \mathbf{R}=\mathbf{C}_{16} \mathrm{H}_{31} ; \mathbf{8} \mathbf{b}_{1}: \mathrm{R}^{\prime}=\mathrm{CH}_{3} ; \mathbf{8} \mathrm{b}_{\mathbf{2}}: \mathrm{R}^{\prime}=\mathrm{C}_{2} \mathrm{H}_{5} ; \mathbf{8} \mathbf{b}_{\mathbf{3}}: \mathbf{R}^{\prime}=\mathrm{C}_{3} \mathrm{H}_{\mathbf{7}}
\end{aligned}
$$

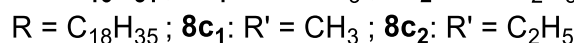

$$
\begin{aligned}
& \mathbf{R}=\mathrm{C}_{18} \mathrm{H}_{33} ; \mathbf{8} \mathrm{d}_{1}: \mathrm{R}^{\prime}=\mathrm{CH}_{3} ; \mathbf{8} \mathrm{d}_{\mathbf{2}}: \mathrm{R}^{\prime}=\mathrm{C}_{2} \mathrm{H}_{5} ; \mathbf{8} \mathrm{d}_{3}: \mathbf{R}^{\prime}=\mathrm{C}_{18} \mathrm{H}_{35} \\
& \mathrm{R}=\mathrm{C}_{18} \mathrm{H}_{31} ; \mathbf{8} \mathbf{e}_{1}: \mathrm{R}^{\prime}=\mathrm{CH}_{3} ; \mathbf{8} \mathbf{e}_{2}: \mathrm{R}^{\prime}=\mathrm{C}_{2} \mathrm{H}_{5} \\
& \mathrm{R}=\mathrm{C}_{18} \mathrm{H}_{29} ; \mathbf{8} \mathrm{f}_{1}: \mathrm{R}^{\prime}=\mathrm{CH}_{3} ; \mathbf{8} \mathrm{f}_{\mathbf{2}}: \mathrm{R}^{\prime}=\mathrm{C}_{2} \mathrm{H}_{5}
\end{aligned}
$$

In this sense, testosterone esterification with caprylic acid (step $d$ in Figure 5) inside the porous architecture of hierarchical (Zr)UiO-66- $\mathrm{NH}_{2} @$ SBA-15 containing 6.6 wt.\% MOF loading resulted in TOF $=0.38 \mathrm{~h}^{-1}$, outperforming the bulk MOF in the absence of SBA-15 (TOF $=0.19 \mathrm{~h}^{-1}$ ). The testosterone uptake (for the same mass of SBA-15, 17 wt.\% MOF@SBA-15 and bulk MOF) was 67,57 and 32 wt.\%, respectively. The increased substrate pre-concentration near the $\mathrm{Zr}$ active sites of the MOF, in the presence of the mesoporous component, favours their activation and functionalization into ester 10 . The carbonyl group of testosterone was also selectively hydrogenated into the allylic alcohol 11 (androst-4-ene-3,17-diol, see Figure 5) 
rather than the saturated ketone or alcohol. Under Luche reduction conditions, compound $\mathbf{1 1}$ was obtained with a rate of 27.6 molecules per $\mathrm{Zr}$ site and hour (TOF $\left.=27.6 \mathrm{~h}^{-1}\right)$ using (Zr)UiO-66- $\mathrm{NH}_{2} @ S B A-15$ with a 6.6 wt.\% MOF loading. In contrast, the TOF of the bulk MOF was only $7.8 \mathrm{~h}^{-1}$.

The group of Llabrés i Xamena compared performance of the wide-pore MOF-808 with UiO-66 in the Meerwein-PonndorfVerley (MPV) reduction of a bulky ketone, known as estrone (dimensions of $11.2 \AA$ x $6.2 \AA$ × $4.2 \AA$ ). ${ }^{66}$ The higher amount of $\mathrm{Zr}$ accessible sites in MOF-808 resulted in almost $90 \%$ conversion of the estrone into estradiol, respect to the marginal conversion (4\%) obtained with UiO-66.

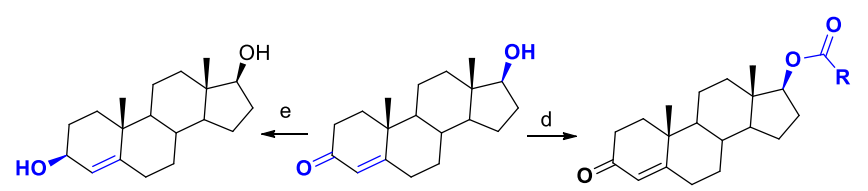

11

9

10: $\mathrm{R}=\mathrm{C}_{8} \mathrm{H}_{15}$

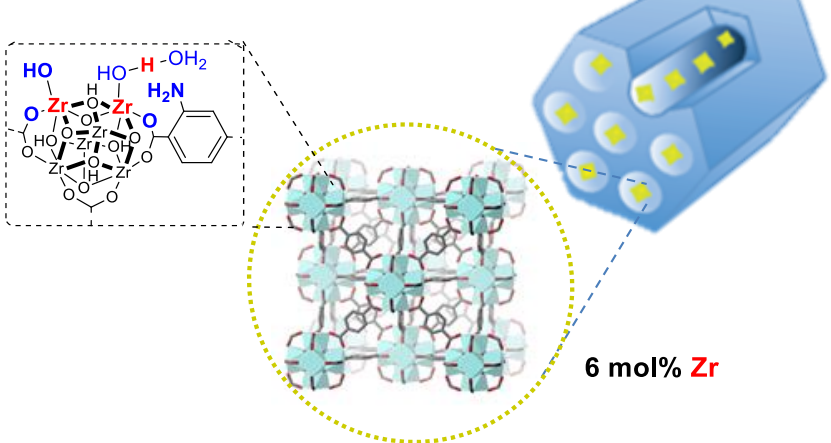

Figure 5. Synthesis of steroid-derived esters and allylic alcohols (Top). (Zr)UiO-66-NH2@SBA-15 containing 6mol\% Zr welldispersed in the mesoporous silica matrix (Bottom).

\subsection{Terpenes: carbonyl-ene reaction and selective hydrogenation}

The precursors of steroids are terpenes, e.g. myrcene (see compound $\mathbf{1 2}$ in Figure 6), which have a great interest in the organic synthesis of fragrances, flavors or pharmaceuticals. In particular, (-)-menthol (15), is natural occurring terpene in the essential oil of mint leaves with medicinal, sensory and fragrant properties due to its action within the central nervous system. For its production, the isomerization of citronellal (13) catalyzed by Lewis acids is a key step that must be performed with high activity and selectivity towards the desired isopulegol diastereoisomer (14).67 Pioneering works by De Vos et al. employed microporous zeolite solids as confined spaces, i.e. Ir/BEA, for the cyclization and hydrogenation steps. ${ }^{68}$ The introduction of metal nanoparticles inside the pores of either silica or MOF-type solids allow the homogeneous distribution of the catalytically active metal nanoparticles, provided that the nanoparticle size is similar to the dimensions of the cavity and preserving the crystalline structure of the MOF.

The mesoporous structure of $(\mathrm{Cr})-\mathrm{MIL}-101$ (see left part of Figure 6) has more than twice the surface area of ( $\mathrm{Zr})$-UiO-66 ( 2500 vs. $1000 \mathrm{~m}^{2} \mathrm{~g}^{-1}$ ), thus being an optimal support for Pd nanoparticles with hydrogenation activity in the step g of Figure
6. In addition, $\mathrm{Cr}^{3+}$-containing MIL-101 MOF shows a high structural stability and coordinatively unsaturated $\mathrm{Cr}^{3+}$ Lewis acid sites, that promotes the citronellal cyclisation inside the confined spaces of the porous structure (step f). 69 TEM microscopy and $\mathrm{N}_{2}$ physisorption indicates the high activity and stability of Pd@MIL-101, which maintains a large fraction of its initial surface area (2100 vs. $\left.1600 \mathrm{~m}^{2} \cdot \mathrm{g}^{-1}\right)$, and only a slight aggregation of the $\mathrm{Pd}$ nanoparticles ( 3 vs. $5 \mathrm{~nm}$ ) after the sequential steps $f$ and $g$ in one-pot.

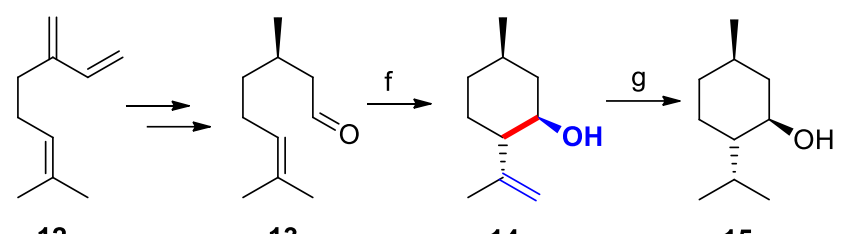

12

13

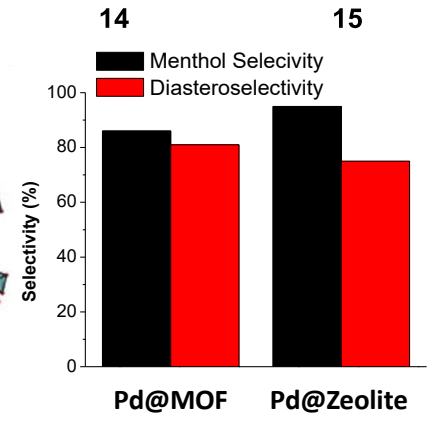

Figure 6. Multi-step synthesis of menthol (top) using Pd nanoparticles confined in MIL-101 (down, left part).

The isomerization of citronellal occurs faster with Pd@MIL-101 with respect to MIL-101, due to the presence of a fraction of unreduced $\mathrm{Pd}^{2+}$ in the mesopores. The presence of reactive metal sites in a Pd pincer Zr-MOF further confirms the high activity of the confined Pd sites (TOF $=144 \mathrm{~h}^{-1}$ ), where framework defects, leading to accessible coordination sites at the $\mathrm{Zr}$ nodes, do not contribute greatly to the observed catalysis with respect to highly active $\mathrm{Pd}(\mathrm{II})$ sites. ${ }^{70}$ The lower cyclization activity of microporous UiO-66 respect to MIL-101 maybe due to the lack of diffusion limitations of isopulegol into the pores of the solid acid, as described for H-MCM-41 and $\mathrm{H}$ MCM-22 zeolites. ${ }^{71}$ However, the UiO-66 type Zr-MOF solids exhibit a high tunability of the pore Lewis/Brønsted acidity of the dehydrated coordinatively unsaturated $\mathrm{Zr}$ sites, which have been carefully investigated in this carbonyl-ene transformation. ${ }^{42,}, 72$

\section{3. $N$-containing molecules: towards a sustainable synthesis of pharmaceuticals}

$\mathrm{N}$-containing molecules are present in natural and synthetic products such as nucleic acids, alkaloids, colorants, agrochemicals and pharmaceuticals. Interestingly, more than $60 \%$ of the small drug molecules on the market contains $N$ heterocyclic molecules, which are synthesized through multiple $\mathrm{C}-\mathrm{C}$ and $\mathrm{C}-\mathrm{N}$ bond formations. ${ }^{73}$ Contemporary organic synthesis relies on selective catalysts which have transition metals in their active sites. This make MOFs ideal reticular 
extension of such discrete transition metal complexes (homogeneous catalyst), ideally isolated in a well-defined periodic and porous matrix (heterogeneous catalyst). As we have described for the synthesis of menthol, the combination of redox active and Lewis acid sites within the same multifunctional porous architecture allows to perform several $\mathrm{C}-\mathrm{C}$ and $\mathrm{C}-\mathrm{N}$ couplings. In this section we will comment mainly on catalytically active transition metal sites able to promote the synthesis of therapeutically relevant aza-molecules. For example, synthetic steps involving condensations in combination with selective hydrogenations using multifunctional catalysts are thoroughly revised in the following section.<smiles>CC(C)(C)C(C[N+](=O)[O-])c1cccc(/C=C/c2ccc(I)cc2)c1</smiles><smiles>CC(C)Cc1cccc(C2CNCC2(C)C)c1</smiles>

23
This samples show a very high activity for the synthesis of $\mathrm{N}$ benzylidene aniline $\left(\right.$ TOF $_{\mathrm{Pd}}=1900 \mathrm{~h}^{-1}$ and $\left.\mathrm{TOF}_{\mathrm{Pt}}=494 \mathrm{~h}^{-1}\right)$. The reductive amination strategy has been employed for the synthesis of aza-heterocycles in one-pot using the mesoporous MOF as host of acid and redox active sites. ${ }^{15}, 16$ 2,5dimethylpyrrole (see compound $\mathbf{1 8}$ in Figure 7) is obtained when 2,5-hexanedione quantitatively reacts with the aniline (17), which is generated from the selective hydrogenation of nitrobenzene (16). MIL-101 and MIL-101- $\mathrm{NH}_{2}$ containing Pd or Pt nanoparticles and salen complexes, respectively, fully convert nitrobenzene into $\mathbf{1 8}$ with full selectivity. In contrast, commercial Pd or Pt nanoparticles dispersed on carbon or

Scheme 3. Four-step cascade synthesis of aryl pyrrolidines (24) from carbonyls and nitro-containing molecules (20).

\subsection{Pyrroles and Pyrrolidines: nitroarene reduction and reductive} amination of carbonyls

One of the most widely employed routes towards primary amines is the reduction of $\mathrm{N}$-containing functional groups (nitro, cyano, azide or carboxamide). For example, nitro groups can be reduced to the corresponding amine employing hydrogen in the presence of metal nanoparticles. Pd nanoparticles fixed inside the regular porous structure of crystalline zeolite Beta give both high activities and excellent selectivities, due to the unique sterically guided adsorption of nitroarenes in the zeolite Beta micropores. ${ }^{74}$ MOFs are suitable supports of noble metals, due to its high porosity with respect to zeolites. Thus, $\mathrm{Pd}$ and $\mathrm{Pt}$ active sites in MIL-101 (see part 2.4) were employed as high performant catalysts to hydrogenate nitro groups with the subsequent amine alkylation using aldehydes (see Figure 7). ${ }^{75}$

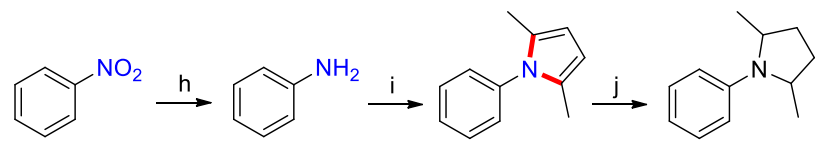

16

17

18

19
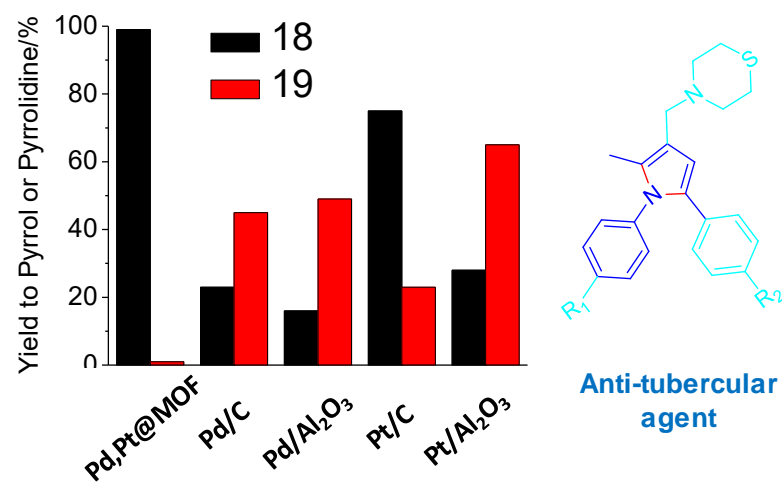

Figure 7. Synthesis of substituted pyrroles with MIL-101 containing $\mathrm{Cr}$ (III) acid sites and Pd or Pt (either as nanoparticles or complexes) hydrogenation sites. alumina yields a mixture of the expected pyrrole (18) and pyrrolidine (19) products. $^{75}$

The same materials were employed as multifunctional catalysts in the one-pot-three-step synthesis of 3-aryl pyrrolidines (see compound $\mathbf{2 4}$ in Scheme 3). The cascade reaction consists in a first Michael addition reaction of isobutyraldehyde to $\beta$ nitrostyrene $\mathbf{2 1}$ (step I), occurring at the acid-base sites of the Pd, Pt@MIL-101. The subsequent selective hydrogenation of the $\gamma$-nitro group of the Michael adduct $\mathbf{2 2}$ at the precious metal sites results in the $\gamma$-amino aldehyde $\mathbf{2 3}$, which condenses and gets further reduced into the desired compound $24 .{ }^{75} \mathrm{~A}$ further reaction step can be added to the sequence, starting from benzaldehyde $\mathbf{2 0}$ (step k), in the presence of acid-base sites, e.g. $\mathrm{Cu}$, amines, etc. ${ }^{76,77}$ Recently, gold nanoparticles in mesoporous silica was tested as solid catalyst on the continuous flow synthesis of high added-value, biomass-derived pyrrolidone product from the reductive amination of levulinic acid with aniline. ${ }^{78}$ It allowed the safe preparation of multigram amounts of reductive amination products (accumulated TON $=434$ in 18 $\mathrm{h}$ involving 6 sequential examples).

The $\mathrm{Ni}_{8}(\mathrm{OH})_{4}\left(\mathrm{H}_{2} \mathrm{O}\right)_{2}(\mathrm{BDP})_{6}$ MOF known as NiBDP, has a porous non-interpenetrated $F C U$ crystalline framework based on octanuclear $\mathrm{Ni}$ (II) clusters connected by BDP $=1,4$-bis (pyrazol4-yl)benzene. ${ }^{41}$ Due to its high chemical stability under basic conditions, NiBDP can be treated with $\mathrm{KOH}$ to generate the linker defective $\mathrm{K}\left[\mathrm{Ni}_{8}(\mathrm{OH})_{6}(\mathrm{BDP})_{5.5}\right]$, known as K@NiBDP (see Figure 8$) .79,80$ The exposed hydroxides of the metal cluster replacing the pyrazolate vacancies and the polar protic functional groups of the BDP linker, e.g. $\mathrm{NH}_{2}$ or $\mathrm{OH}$, increases its catalytic activity with respect to the parent NiBDP. The TOF of NiBDP vs. K@NiBDP for nitro aldol condensation $\left(0.04 \mathrm{~h}^{-1}\right.$ vs. $\left.0.05 \mathrm{~h}^{-1}\right)$ and Michael addition $\left(0.4 \mathrm{~h}^{-1}\right.$ vs. $\left.1.0 \mathrm{~h}^{-1}\right)$ reactions, confirms the participation of the basic $\mathrm{OH}$ sites in the reaction mechanism of steps $\mathrm{k}$ and I of Scheme $3 .^{76}$ 


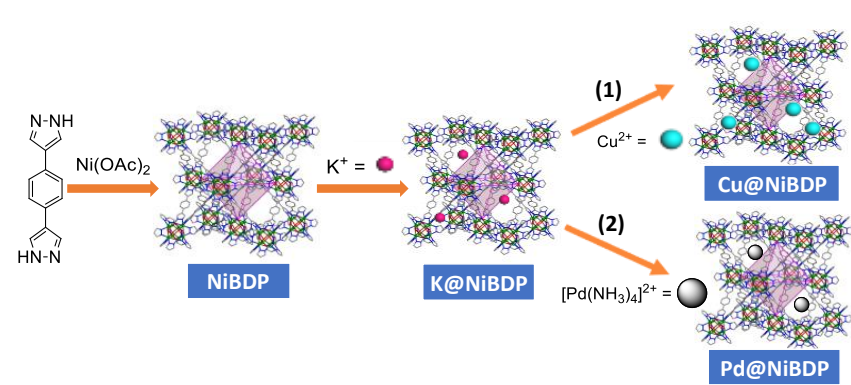

Figure 8. Tuning activity of NiBDP through ion exchange with $\mathrm{Cu}$ (1) or Pd (2).

The presence of extraframework $\mathrm{K}^{+}$opens the way to ionexchange with catalytically active transition metals, such as $\mathrm{Cu}$ or Pd (see Figure 8). On the one hand, the copper sites incorporated increases the TOF of the resulting Cu@NiBDP catalyst up to 0.08 and $1.2 \mathrm{~h}^{-1}$ for nitro aldol and Michael additions, respectively. The number of molecules of $\beta$ nitrostyrene per $\mathrm{Cu}$ or $\mathrm{Ni}$ site is twofold when copper is incorporated in the MOF, respect to their homogeneous counterparts (see Figure 9a and b).

Noteworthy, this values are lower than those obtained with organocatalysts in the confined spaces of MOFs, ${ }^{81}$ such as the lysine amino acid incorporated in MOF-808 (TOF > $20 \mathrm{~h}^{-1}$ for the nitro aldol reaction at 30 -C). ${ }^{77}$ The values of the transition state enthalpy of the nitroaldol condensation was experimentally calculated to be $6 \mathrm{~kJ} \cdot \mathrm{mol}^{-1}$ lower using the high performant aminopropyl functionalized $\mathrm{MCM}-41$ silica $\left(\Delta \mathrm{G}^{\neq}=77 \mathrm{~kJ} \cdot \mathrm{mol}^{-1}\right)$ respect to Lysine/MOF-808 $\left(\Delta \mathrm{G}^{\neq}=83 \mathrm{~kJ} \cdot \mathrm{mol}^{-1}\right)$.

Furthermore, $\mathrm{Pd}$ catalytic species were immobilized in the same NiBDP porous framework (pore aperture $\sim 1.6 \mathrm{~nm}$ ) for the $\mathrm{C}-\mathrm{H}$ activation of terminal alkynes. ${ }^{82}$ The surface area of K@NiBDP MOF decreases from $2060 \mathrm{~m}^{2} \cdot \mathrm{g}^{-1}$ to $1131 \mathrm{~m}^{2} \cdot \mathrm{g}^{-1}$ after the filling of the micro and mesopores with catalytically active confined $\left[\mathrm{Pd}\left(\mathrm{NH}_{3}\right)_{4}\right]^{2+}$ species (5.6 wt.\% Pd in Pd@NiBDP). The Pd nanoparticles are in the same oxidation state and homogeneously dispersed, as indicated by UV/Vis absorption spectra, X-ray photoelectron spectroscopy analysis, high resolution transmission electron microscopy imaging and energy dispersive $\mathrm{X}$-ray spectroscopy mapping. The $\mathrm{Pd}(\mathrm{II})$ active sites in the MOF pores favours the alkyne hydroamination with high activity (Figure 9c) and selectivity with respect to alkyne hydration (Figure 9d). This competitive water promoted reaction takes place when acid supports are employed, e.g. zeolite H-USY, which also show diffusion problems for intermolecular hydroamination (pores of only $0.7 \mathrm{~nm}$ ). Moreover, the interactions of the cationic Pd species with the $\mathrm{N}$-containing pyrazolate and exposed hydroxides of the
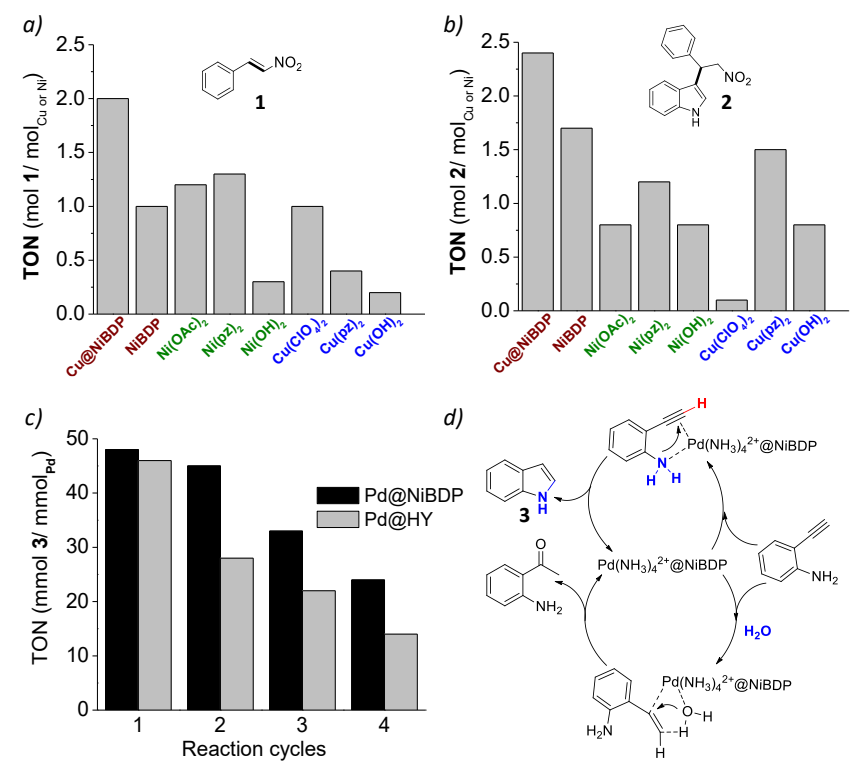

Figure 9. Catalytic activity of Cu@NiBDP and Pd@NiBDP in the Henry (a), Michael (b) and hydroamination (c), together with a plausible mechanism (d).

defective framework are stronger than the interactions with the oxygen of the FAU silicate. The cumulative TON after 4 reaction cycles is 150 , in line with the best reported $\mathrm{Pd}(\mathrm{II})$ catalysts, e.g. Pd-pincer complexes on $\mathrm{Zr}$-MOFs (TON = 20), $83 \mathrm{NHC}$-palladium complexes $(\mathrm{TON}=198),{ }^{84}$ or $\mathrm{PdCl}_{2}(\mathrm{TON}=88) .85$

\subsection{Quinolines and Pyranoquinolines: enol-type additions, condensations and Diels-Alder cycloadditions}

If we combine the tailored hydrogenating MOFs (Pd, Ptcontaining MIL-101 samples) presented in the previous section with a second type of active sites, aldol condensation steps can be further added to the tandem nitroarene reduction and intramolecular reductive amination sequences. For example, step $(\mathrm{m})$ in Scheme 4, allows the access to the synthesis of quinolones (28) or tetrahydroquinolines (29), starting form compounds containing the nitro and carbonyl functions (26) at the appropriate distance to generate the corresponding 6member $\mathrm{N}$-heterocyclic ring. ${ }^{86}$

CuO-MOF derived nanoparticles supported on acid aluminosilicates, i.e. $\mathrm{H}-\mathrm{USY}$ and $\mathrm{H}-\mathrm{MCM}-41(\mathrm{Al})$, are almost two orders of magnitude more active than the bulk $\mathrm{Cu}_{3}(\mathrm{BTC})_{2} \mathrm{MOF}$ precursor ( $\mathrm{TOF}_{\mathrm{Cu}} \sim 80$ vs. 1, respectively) in the Friedlander condensation of 2-aminobenzophenone with acetylacetone (step $\mathrm{m}$ and $\mathrm{I}$ in Scheme 4). ${ }^{87}$ The use of $\mathrm{Cu}_{3}(\mathrm{BTC})_{2}$ as precursor of $\mathrm{CuO}$ active sites instead of $\mathrm{Cu}(\mathrm{OAc})_{2}$ remarkably improves the catalytic activity of the copper containing zeolite ( $\mathrm{TOF}_{\mathrm{Cu}} \sim 70 \mathrm{vs}$. 10, respectively). Recently, Cu-MOFs with basic nitrogen BPY<smiles>[R]C(=O)c1ccccc1[N+](=O)[O-]</smiles>

25<smiles>[R]C(=O)C([R20])=C([R])c1ccccc1[N+](=O)[O-]</smiles><smiles>[R]C(=O)C([R])=C([R])c1ccccc1N</smiles><smiles>[R]C1Nc2ccccc2C([R])C1[R]</smiles>

29

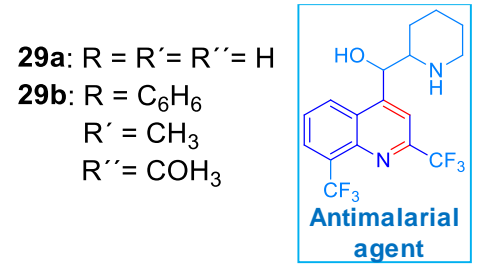
agent

Scheme 4. Four-step cascade synthesis of quinolones (28) and tetrahydroquinolines (29) from carbonyls and nitro-containing molecules (25). 
ligands under oxidant conditions (e.g. TEMPO), are employed as catalysts for the synthesis of 3-arylquinolines via one-pot domino radical-type reactions of 2-aminobenzylalcohols with propiophenones. ${ }^{88}$ The same MOF system allowed the synthesis of benzoxazines or benzimidazoles under similar oxidative couplings. ${ }^{89}$

The Zr-containig MOFs of the UiO-66 type, described in part 2 of this contribution, have been employed as acid catalysts in the synthesis of pyrano[3,2-c]quinolines (see compound 32 in Figure 10). The sequence consists of an inverse electrondemand aza-Diels-Alder [4+2] cycloaddition of an arylamine (31), formed in situ from aniline and benzaldehyde (30), and electron-rich 3,4-dihydropyran. ${ }^{90}$ The acid sites present at the $\mathrm{Zr}$-oxo clusters catalyzed the activation of the imine through $\mathrm{Zr}^{4+}-\mathrm{N}$ or $\mathrm{H}^{+-} \mathrm{N}$ interactions. The [4+2] cycloaddition of 3,4dihydropyran to the activated imine, selectively take place from the exo approach

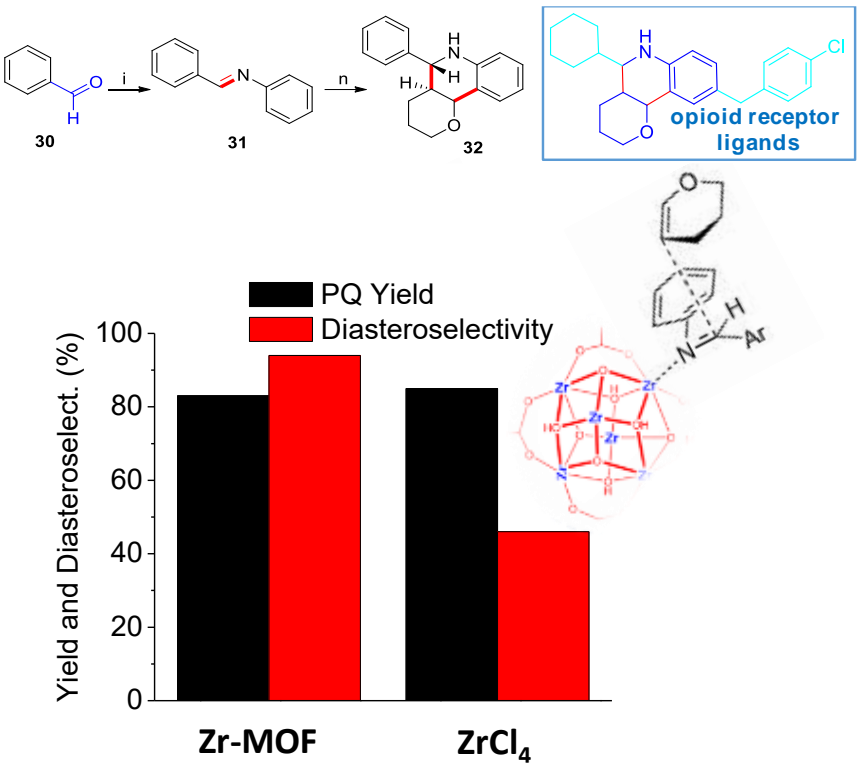

Figure 10. Hetero-Diels-Alder synthesis of pyranoquinolines ( $P Q$ 32) using $\mathrm{Zr}$ heterogeneous ( $\mathrm{Zr}$-UiO-66 MOF) or homogeneous $\left(\mathrm{ZrCl}_{4}\right)$ catalysts.

which determine the formation of the trans $\mathbf{3 2}$ product with a diastereomeric excess of 94 vs. 46 for UiO-66 and $\mathrm{ZrCl}_{4}$, respectively (see Figure 10). In this sense, the embedded $\mathrm{Zr}$ sites within the BDC ligands results in steric hindrance that control the orientation of the intermediates resulting in the observed stereoselectivity. The activity of the UiO-66 increases proportionally to the inverse of their particles sizes (TOF $=6.5 \mathrm{~h}$ ${ }^{1}$ vs. $2.8 \mathrm{~h}^{-1}$ for 45 or $60 \mathrm{~nm}$, respectively), due to the increased surface-to-volume ratio and defect content, as described for (Zr)UiO-66- $\mathrm{NH}_{2} @$ @BA-15.65 Interestingly, (Cr)MIL-101, having larger porous cavities than UiO-66, show much lower activity, probably due to the high polarizing power $\left(Z^{2} / r\right)$, and thus Lewis acidity, of $\mathrm{Zr}^{4+}$ respect to $\mathrm{Cr}^{3+}$ in the activation of the imine $\mathbf{3 1}$. Regarding to silica-based materials, tungstophosphoric acid $(0.5$ mol\%) on MCM-41 mesoporous silica show $88 \%$ yield of pyranoquinoline in just $2.2 \mathrm{~h}$ (TOF $=80 \mathrm{~h}^{-1}$ ), which outperforms in activity the UiO-66 MOF (TOF $\left.=2 \mathrm{~h}^{-1}\right) \cdot{ }^{91}$ However, the diastereomeric excess (d.e.) of the trans $\mathbf{3 2}$ product is higher in the presence of the MOF (d.e. $=94 \%$ ) respect to the silica (d.e. $=16 \%$ ), which shows a lower preference for the trans product. Furthermore, H-USY zeolite containing Sc(III) cations with high dispersion inside their pores was used as catalyst for the synthesis of tetrahydroquinoline derivatives through the [4+2] cycloaddition reaction between $\mathrm{N}$-arylimines and alkenes..$^{92}$ Interestingly, high metal loading results in the incorporation of more than one scandium ion within the zeolite pores, almost obstructing these pores and thus inhibiting catalysis (TON $=20$ vs. 2 for the $2 \%$ and 30 mol\% loaded samples).

\subsection{Substituted indoles, oxindoles and spiroxoindoles: Aldol condensation and Friedel-Crafts alkylations}

The aldol condensation / oxa-Diels-Alder reaction of isatin $(1 \mathrm{H}-$ indole-2,3-dione) with an hetero diene ( $\alpha, \beta$-unsaturated ketone) is 1-2 orders of magnitude faster with MOF-derived ZnO nanoparticles well-dispersed in aluminosilicates than the pure or calcined Zn-MOF-5 (see Scheme 5). ${ }^{87}$ This novel MOF/silicacatalyst methodology indicates the importance of $\mathrm{H}^{+} / \mathrm{ZnO}$ acidbase sites within a single material. The particular use of the porous crystalline $\mathrm{H}$-USY zeolite with respect to amorphous $\mathrm{SiO}_{2}$ increases the TOF in more than $120 \%$, due to the better dispersion and accessibility to the zeolite acid sites. Other spirotype compounds, known as spirodibenzo[b,e][1,4]oxazepines, were prepared starting from isatins, 2-amino phenols and cyclic-1,3-diketones with the aid of recyclable $\mathrm{Na}-\mathrm{Y}$ zeolite nanopowder ( $\mathrm{Si}: \mathrm{Al}=1.5$ ) catalyst. $^{93}$ The acid sites present at the Y zeolite activate the carbonyl oxygen atom of the isatin moiety making it more electrophilic, which eventually produce 3 molecules of the spiro-type compound per acid site, a similar turnover number to that obtained with homogeneous acids such as trifluoroacetic or acetic acids. However, the cumulative zeolite TON after 6 reaction cycles increases up to 16, highlighting the benefit of heterogeneous acid catalysts over corrosive and non-reusable homogeneous ones.

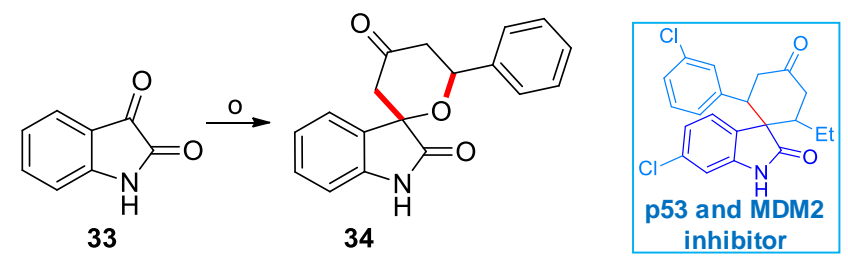

Scheme 5. Synthesis of spirooxoindole $\mathbf{3 4}$ from isatin $\mathbf{3 3}$

The same MOF derived $\mathrm{ZnO} /$ silica materials were also employed as catalyst in the synthesis of substituted oxindoles such as 3benzyliden-2-oxindole (see compound $\mathbf{3 6}$ in scheme 6), through the aldol condensation between oxindole (35) and benzaldehyde (step $\mathrm{p}$ ). The same reaction was catalyzed by modified SBA-15- $\mathrm{Pr}-\mathrm{SO}_{3} \mathrm{H}$ acid mesoporous silica, which protonates the carbonyl group of benzaldehyde, and then condenses with oxindole $\mathbf{3 5}$ to give the adduct product which is converted to target molecule $\mathbf{3 6}$ after dehydration. ${ }^{94}$ 
<smiles>[R]C=C1C(=O)Nc2ccc(CCPc3cc4ccccc4[nH]3)cc21</smiles><smiles>Cc1cccc(-c2ccccc2)c1</smiles>

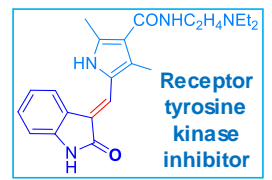

Scheme 6. Synthesis of substituted oxindoles through aldol condensation

The aldol condensation (step $q$ in Scheme 7) between benzaldehyde and epiandrosterone ( $5 \alpha$-androstan-3 $\beta$-ol-17one) or estrone (37) generates important intermediates in the synthesis of anticancer drugs based on steroidal spiroxoindoles. The use of homogeneous base catalysts can be replaced by heterogeneous ones (such as mesoporous $\mathrm{Zr}-\mathrm{MOF} @ \mathrm{SiO}_{2}$ or $\mathrm{H}-$ USY zeolites) resulting in TOFs up to $5 \mathrm{~h}^{-1}$, with long term stability during several cycles upon MOF washing or zeolite calcining. ${ }^{65,} 95$ The improved diffusion of bulky steroids in the large ordered porous systems increases its pre-concentration at the active site and further conversion into steroid $\mathbf{3 8}$.

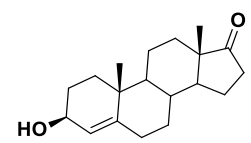

37

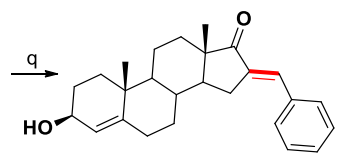

38

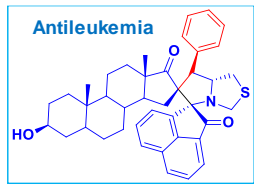

Scheme 7. Synthesis of functionalized steroid derivatives.

Acid catalyzed Friedel-Craft alkylation of aromatic rings with alcohols is a sustainable method for the $\mathrm{C}-\mathrm{H}$ functionalization of indoles. Zr-MOFs as well as zeolite H-USY containing different degrees of mesoporosity and strong acid sites are able to promote the alkylation of the indole by protonating the alcohol alkylating agent.95, 96 Simple activated alcohols such as 4methoxy- $\alpha$-methylbenzyl alcohol generates compound 40a (see Scheme 8) with TOFs of 15 and $114 \mathrm{~h}^{-1}$ for the (Zr)UiO-66 MOF and H-USY zeolite, respectively. ${ }^{96}$ The best performant porous zeolite solid can further improve its activity in the synthesis of larger substituted indoles by incorporation of mesoporosity in the USY structure. ${ }^{95}$ Interestingly, in the case of using larger alcohols such as benzoin ( $\alpha$-hydroxy- $\alpha$-phenylacetophenone, see $40 \mathrm{~b}$ in Scheme 8 ), the critical diameter of the molecule $(0.76$ $\mathrm{nm})$ slightly exceeds the pore window size of the FAU zeolite $(0.74 \mathrm{~nm})$. Thus, the TOF of the hierarchical zeolite is one magnitude higher than that of the microporous one (20 vs. $1 \mathrm{~h}$ 1 , respectively), due to the better accessibility of the bulky

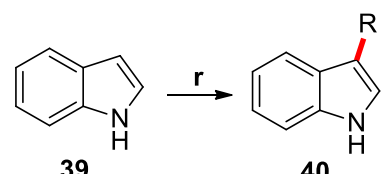

39 40a: $\mathrm{R}=$<smiles>COc1ccc(C(C)C)cc1</smiles>

40b: $\mathrm{R}=\mathrm{Ph} \underbrace{\mathrm{O}}_{\mathrm{Ph}}$

40c: $R=$<smiles>CCc1ccc(OC)c(OC)c1</smiles>

Scheme 8. C-H functionalization of indole through its alkylation using different alcohols.

alcohol to the inner Brønsted acid sites. ${ }^{95}$ A good accessibility is also observed with the same active sites dispersed in ionic show improved molecular transport to the embedded acid sites. ${ }^{96}$

Both ionic liquids or MOFs have been demonstrated to be tunable quasi-homogeneous or heterogeneous, respectively, catalysts for the alkylation of indoles with alcohols. ${ }^{96}$ This is due to the possible incorporation of several acid cations with increased hardness or polarizing power, e.g. $\mathrm{Zn}^{2+}, \mathrm{Fe}^{3+}, \mathrm{Cr}^{3+}, \mathrm{Al}^{3+}$, $\mathrm{Zr}^{4+}$, in the ionic liquid or metal-organic frameworks. The relationship between the catalytic activity and electronic properties of the acid metal (charge/size ratio) is shown in Figure 11 . The higher catalytic activity of hard Lewis acids, e.g. $\mathrm{Al}^{+3}$ or $\mathrm{Zr}^{+4}$, respect to softer ones, e.g. $\mathrm{Zn}^{2+}$ is a common trend. This is illustrated on the right part of the figure, where the nature of the active sites consists of strong Lewis acid sites containing polarized water molecules that results in Brønsted acid sites able to protonate the alcohol into carbocationic alkylating species. ${ }^{42}$

Figure 11. Initial reaction rate vs. charge/size of the catalytic
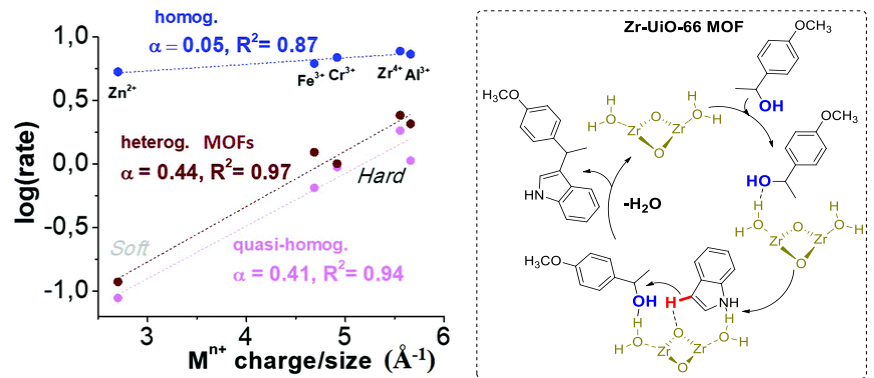

metal site (left) and tentative mechanism for ( $\mathrm{Zr}$ )UiO MOF type catalyst (right).

The direct activation of $\mathrm{C}(\mathrm{sp})-\mathrm{H}$ and $\mathrm{C}\left(\mathrm{sp}^{2}\right)-\mathrm{H}$ bonds make use of transition metal catalysts that are often expensive and unstable, not allowing for long term applications and requiring harmful additives in large amounts. We have previously described the intermolecular hydroamination of 2-ethynylaniline 41 using $\mathrm{Pd}(\mathrm{II})$ active sites on NiBDP MOF, through the $\mathrm{C}(\mathrm{sp})-\mathrm{H}$ and $\mathrm{N}-\mathrm{H}$ activation and further coupling of the alkyne and amino groups (see Figure $9 \mathrm{c}$, $d$ and step s in Scheme 9). ${ }^{[82]}$ However, the TON of c.a. 50 obtained with the Pd containing MOF for substrate 41 is below the best results reported in the hydroamination of o(phenylacetylen)aniline using the zeolite $\mathrm{Pt}(\mathrm{II})-\mathrm{HY}$ (TOF $=375$ $\left.\mathrm{h}^{-1}\right) \cdot{ }^{97}$ Other Pt-supported catalysts including Pt on carbon and

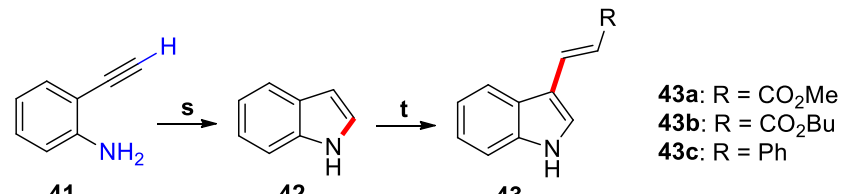

42

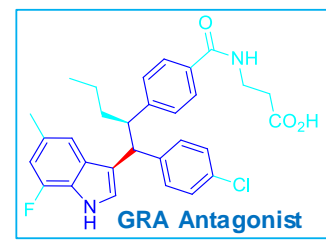

43

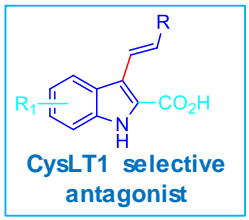

Scheme 9. Two step synthesis of substituted indoles 
Pt supported on alumina or silica-alumina gave TOF values $<10$ $\mathrm{h}^{-1}$, highlighting the higher stabilization of Pt sites in the zeolite pores.

The resulting indole $\mathbf{4 2}$ can be further functionalized at the $\mathrm{C}\left(\mathrm{sp}^{2}\right)-2$ position through room temperature alkenylation with a second $\mathrm{C}\left(\mathrm{sp}^{2}\right)-\mathrm{H}$, generating compound 43. In order to overcome the limitations of homogenous $\mathrm{Pd}(\mathrm{OAc})_{2} /$ acid systems, we have proposed MOF-74 as a nanoreactor (pore dimensions of $1 \times 1.4 \mathrm{~nm}$ ) for the $\mathrm{Pd}(\mathrm{II})$ catalysed C-C cross coupling. ${ }^{98}$ The encapsulation of $\mathrm{Pd}(\mathrm{OAc})_{2}$ and $\mathrm{H}_{3} \mathrm{PW}_{12} \mathrm{O}_{40}$ (POM) into the pores of the Cu-MOF74 results in a surface area decrease from 1120 to $480 \mathrm{~m}^{2} \cdot \mathrm{g}^{-1}$, with no destruction of the structure (as indicated by PXRD), suggesting more than $50 \%$ occupied porosity. The number of molecules of compound $\mathbf{4 3 b}$ generated per $\mathrm{Pd}$ atom is three times higher when those sites are in the MOF, respect to those in a solution ( $\left.\mathrm{TON}_{\mathrm{Pd}} \sim 15\right)$. In contrast, the $[\mathrm{Pd} / \mathrm{Cu}] / \mathrm{NaY}$ zeolite shows a TON of 10 , using 60 equivalents of acetic acid. ${ }^{99}$
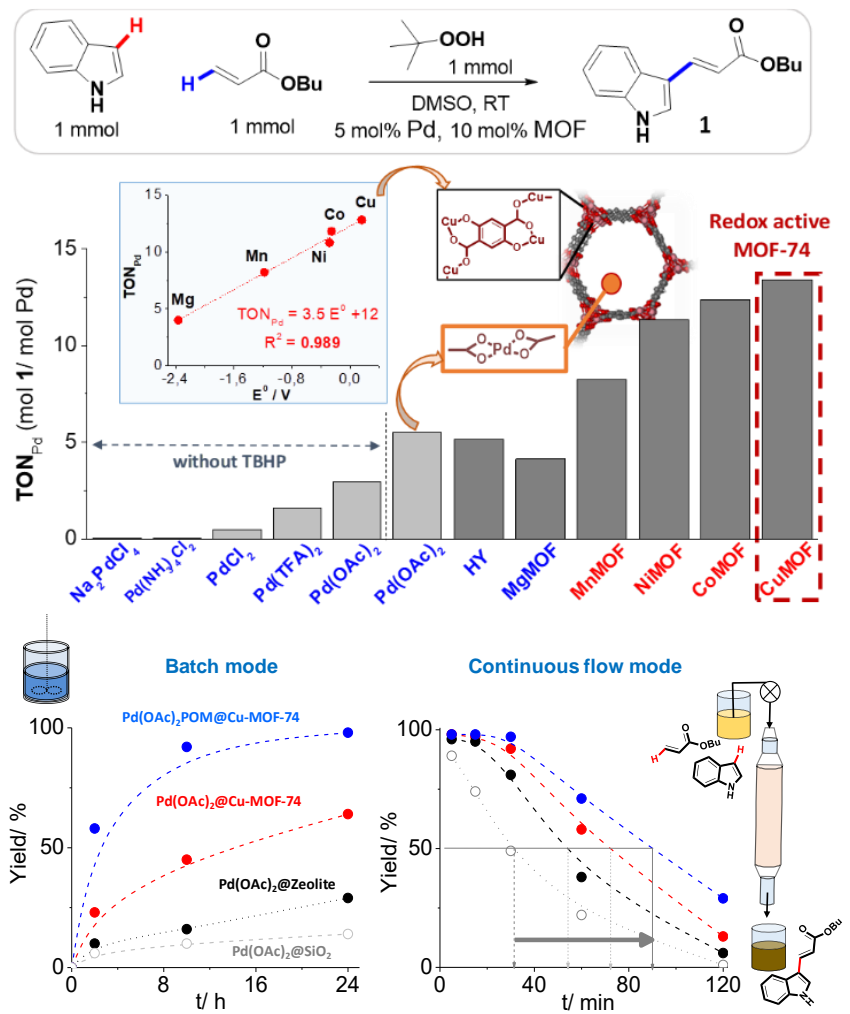

Figure 12. Alkenylation of indole with butyl acrylate catalysed by POM/Pd(OAc) $)_{2} @ M O F-74$ in batch or continuous flow mode.

A linear trend between the catalytic activity and reduction potential of the divalent metals from the MOFs (i.e. $\mathrm{Mg}, \mathrm{Mn}, \mathrm{Ni}$, $\mathrm{Co}, \mathrm{Cu}$ ) was observed, indicating the re-oxidation of the electrophilic $\mathrm{Pd}$ (II) sites by the redox active MOF (see top part of Figure 12), which maintain its crystalline structure after reaction. Even under continuous flow conditions, the lifetime of $\mathrm{Pd}(\mathrm{II})$ sites is increased with more than $270 \%$ for the Pd/POM$\mathrm{Cu}-\mathrm{MOF}$ support in comparison with using a silica matrix. The decrease in activity after $0.5-2 \mathrm{~h}$ of reaction might be due to two main factors: (i) loss of $\mathrm{Pd}$ (II) active sites from the pores of the MOF, given the surface area changes of the solid catalyst (480 and $790 \mathrm{~m}^{2} \mathrm{~g}^{-1}$ for the fresh and spent Pd/POM-Cu-MOF); (ii) reduction of the remaining $\mathrm{Pd}(\mathrm{II})$ encapsulated to inactive $\mathrm{Pd}(0)$ during the reaction, given the Pd-Pd XAS band observed in the spent Pd-MOF. In this sense, the distribution of the $\mathrm{Pd}(0)$ nanoparticles over the framework of 1,2,4,5benzenetetracarboxylate-(Zr)UiO-66 MOF after this type of couplings was recently studied by Van Velthoven et al. ${ }^{[100]}$ The dispersion of $\mathrm{Pd}(\mathrm{OAc})_{2}$ trimers into monomeric MOF-supported $\mathrm{Pd}$ species was favored by the exchange of the acetate ligands with the "free" carboxylate ligands in the MOF pores, indicated by the increase in the Pd-O bond after Pd loading on the MOF $\left(d_{P d-O}=1.6\right.$ vs. $1.9 \AA$ A $)$.

\subsection{Propargilamines: alkynylation and amination}

Indole and imidazopyridine derivatives were prepared by Luz et al. through one-pot C-C and C-N bond forming reactions based on alkynylation and amination multi-component reaction of aldehydes, amines, and amines (A3 coupling) catalyzed by copper MOFs. ${ }^{101}$ Despite the good product yields and reusability, the TOF of the $\mathrm{Cu}(2-\text { pymo })_{2} \mathrm{MOF}$ catalysts was smaller than that of the homogeneous $\mathrm{CuCl}_{2}$ catalyst (7 vs. $70 \mathrm{~h}^{-}$ 1). However, while the $\mathrm{Cu}$ homogeneous catalyst favors the homo-coupling of the alkyne, the MOF shows high selectivity to the desired imidazopyridine. Other metal-organic frameworks, such as $\mathrm{Cu}_{2}(\mathrm{BPDC})_{2}$ (BPY) (BPDC = biphenyldicarboxylate; $\mathrm{BPY}=$ bipyridine), were synthesized and used as a heterogeneous catalyst for the copper-catalyzed A3 reaction of tetrahydroisoquinoline, aldehydes and alkynes to form C1alkynylated tetrahydroisoquinolines, with high regioselectivity to the endo-yne-product. ${ }^{102}$

Recently, we have supported MOF derived CuO nanoparticles on $\mathrm{H}$-USY zeolite $\left(\mathrm{CuO}_{\mathrm{MOF}} \mathrm{Y}\right)$, as a straightforward catalytic system for couplings of alkyne, aldehyde and amine groups of different molecules. This results in the MOF-derived/ $/ \mathrm{SiO}_{2}-$ catalyzed synthesis of propargylamines in high yields (see $\mathbf{4 5}$ in Figure 13 ) based on the use of pyperidine $\mathbf{4 5 a}$, morpholine $\mathbf{4 5 b}$ or pyrrolidine $45 \mathrm{c}$ in the presence of the solid catalyst. ${ }^{87}$ The TOF of the $\mathrm{CuO}_{\mathrm{MOF}} \mathrm{Y}$ is one order of magnitude higher than bulk CuO derived from the MOF, starting MOF and other silica supports or $\mathrm{Cu}$ precursors, e.g. $\mathrm{Cu}(\mathrm{OAc})_{2}$.

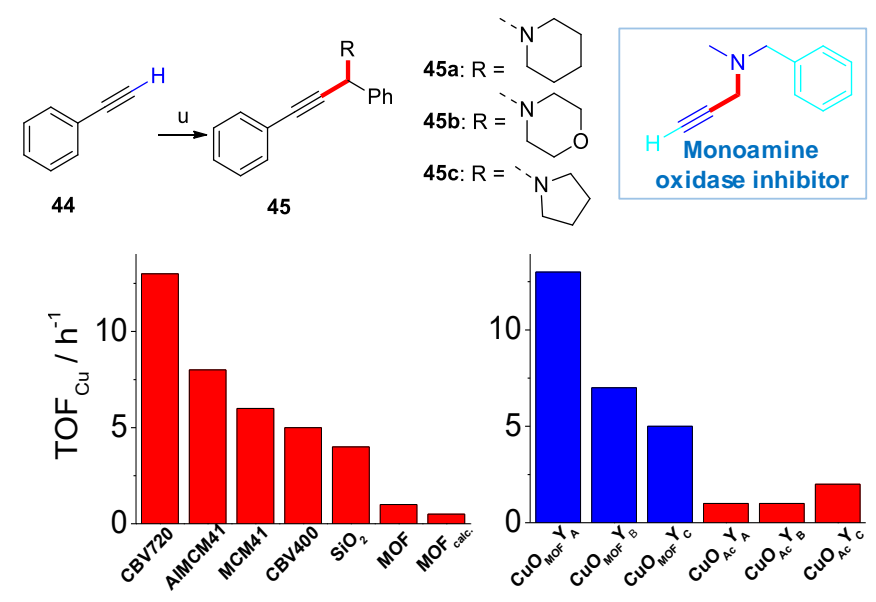

Figure 13. Synthesis of propargylamines through A3 coupling catalysed by MOF derived $\mathrm{CuO}$ on aluminosilicate supports. 


\subsection{Nucleoside analogues: condensations and alkenylations}

Zn-IRMOF-3 was a successful catalyst for the one-pot synthesis of dihydropyrimidinone and dihydropyridine derivatives through the Biginelli and Hantzsch condensation of aldehydes and acyclic $\beta$-diketones with ammonia or urea without any solvent, salts and additives (TOF $=7 \mathrm{~h}^{-1}$, TON $\left.=20\right) .{ }^{103}$ Important pyrimidinedione scaffolds are found in $\mathrm{C}-5$ substituted uracil type enamine-like $\mathrm{N}$-heterocyclic arenes. Those are important antitumor and antiviral compounds which can be prepared by alkenylation with acrylates (see Scheme 10). ${ }^{98}$ The TON values of $\mathrm{Pd}$ on MOFs are moderate ( 4 vs. 15 in the case of indole substrate), but the reaction rate duplicates with respect to nonredox active zeolitic supports. Importantly, the redox active $\mathrm{Cu}$ MOF-74 can be recycled in the presence of fresh $\mathrm{Pd}(\mathrm{OAc})_{2}$, enhancing its activity in several cycles.
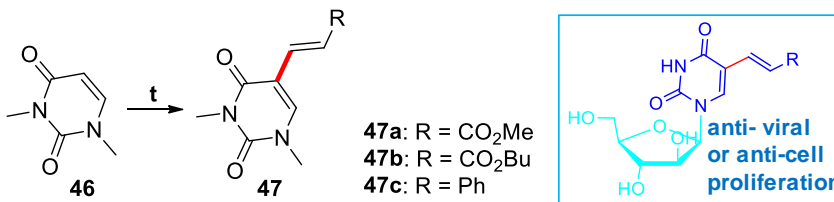

Scheme 10. Functionalization of pyrimidinediones with simple alkenes.

\section{Summary and Outlook}

The synthesis of complex organic molecules is currently based on homogeneous reagents or catalysts which show a good performance in terms of activity and selectivity. The novel discoveries in the field of ordered porous materials, from zeolites to MOFs, offers new possibilities in the incorporation of one or several active sites to promote organic synthesis steps. Among them, acid-base or redox active sites in the framework of hybrid inorganic-organic materials are the most studied. They offer a good performance, i.e. activity, selectivity and stability, in multiple $\mathrm{C}-\mathrm{C} / \mathrm{C}-\mathrm{N}$ bond formations (condensations, dehydrations, alkylations, alkenylations, etc.) and/or the selective interconversion of functional groups (reductions and oxidations).

The solid nature of the MOFs/Silica catalysts represents and advantage over soluble ones in liquid organic transformations, given the simple, clean and efficient recovery from the reaction media and the possibility of recycle. Not only the environmentally benign nature is interesting from the fundamental point of view, but the possibility to design the catalyst in a controlled and rational manner based on the periodicity of their structures. The crystalline nature allows to model the structure of the active site through the solid particles, and to understand and modify at will its chemical reactivity in multiple organic steps. Since many organic molecules employed as pharmaceuticals exceed the size of the pores of traditional zeotypes, i.e. 0.2-1 nm, the discovery of new synthetic routes towards mesoporous MOFs or silica, i.e. 1-20 nm, with high tunability in pore size, shape and functionality represents future avenues where the science of heterogeneous organic chemistry will transit.
Last decade (2010-2020) represents an exponential growth in metal-organic framework catalysis research for organic synthesis transformations. We are confident that the next years will show more innovative and high performant (more active, selective and stable) MOF-type catalysts for the synthesis of high added value molecules, as well as other important products for society, such as petrochemicals, bulk chemicals or fuels. On the one hand, MOFs will offer an almost infinite number of possible combinations of active sites, e.g. coordinatively unsaturated metals, metal or metal oxide nanoparticles, transition metal complexes, organic groups, etc. On the other hand, the active sites will be incorporated at the desired framework locations, either at the pore cavities, nodes or linkers, through novel solid-state chemistry. The enormous amount of crystalline porous architectures exhibited by this new class of porous materials, will serve as inspiration to design a particular confined environment, thus modifying at will the steric and electronic properties of the active site. All this will represent an extraordinary versatility and rational design of the geometry and functionality of confined spaces in reticular materials, with the aim of carry on efficient and clean organic transformations, never seen before with traditional ordered porous solids or even homogeneous catalysts.

\section{Conflicts of interest}

There are no conflicts to declare.

\section{Acknowledgements}

F. G. Cirujano acknowledges the support of a fellowship from "la Caixa" Foundation (ID 100010434). The fellowship code is LCF/BO/PI19/11690011. N. Martín acknowledges the "Juan de la Cierva formación" fellowship with code FJC2018-035455-I

\section{Notes and references}

1 H.-U. Blaser, M. Studer, Appl. Catal. A 1999, 189, 191.

2 C. A. Busacca, D. R. Fandrick, J. J. Song, C. H. Senanayake, $A d v$. Synth. Catal. 2011, 353, 1825.

3 J. D. Hayler, D. K. Leahy, E. M. Simmons, Organometallics 2019, 38, 36

4 J. Liang, Z. Liang, R. Zou, Y. Zhao, Adv. Mater. 2017, 29, 1701139.

5 A. Corma, Angew. Chem. Int. Ed. 2016, 55, 6112.

6 L. Malet-Sanz, F. Susanne, J. Med. Chem. 2012, 55, 4062.

7 R. Porta, M. Benaglia, A. Puglisi, Org. Process. Res. Dev. 2016, 20, 2.

8 J. Britton, C. L. Raston, Chem. Soc. Rev. 2017, 46, 1250.

9 Sharma, Van der Eycken (Eds.), Flow Chemistry for the Synthesis of Heterocycles 2018, Springer.

10 K. Masuda, T. Ichitsuka, N. Koumura, K. Sato, S. Kobayashi, Tetrahedron 2018, 74, 1705.

11 J. C. McWilliams, A. D. Allian-Suzanne, M. Opalka, S. A. May, M. Journet, T. M. Braden, Org. Process. Res. Dev. 2018, 22, 1143.

12 D. E. De Vos, M. Dams, B. F. Sels, P. A. Jacobs, Chem. Rev. 2002, 102, 3615.

13 A. Corma, H. Garcia, Adv. Synth. Catal. 2006, 348, 1391. 
14 A. Dhakshinamoorthy, A. M. Asiri, H. Garcia, Chem. Soc. Rev. 2015, 44, 1922.

15 F. G. Cirujano, F. X. Labres i Xamena in Organic Nanoreactors (Ed.: S. Sadjadi), Elsevier, 2016, pp. 305-340.

16 F. Llabrés i Xamena, I. Luz, F. G. Cirujano in Metal Organic Frameworks as Heterogeneous Catalysts (Eds. F. L. Xamena, J. Gascon), RSC, 2013, pp. 237-267.

17 S. Yang, L. Peng, S. Bulut, W. L. Queen, Chem. Eur. J. 2019, 25, 2161.

18 [18] H. Konnerth, B. M. Matsagar, Season S. Chen, M. H. G. Prechtl, F.-K. Shieh, K. C.-W. Wua, Coord. Chem. Rev. 2020, 416, 213319.

19 A. Bavykina, N. Kolobov, S. Khan, J. A. Bau, A. Ramirez, J. Gascon Chem. Rev. 2020, doi.org/10.1021/acs.chemrev.9b00685.

20 S. Kousik, S. Velmathi, Chem. Eur. J. 2019, 25, 16451.

21 A. Dhakshinamoorthy, M. Alvaro, A. Corma, H. Garcia, Dalton Trans. 2011, 40, 6344.

22 F. G. Cirujano, Catal. Sci. Technol. 2017, 7, 5482-5494.

23 M. Opanasenko, A. Dhakshinamoorthy, M. Shamzhy, P. Nachtigall, M. Horáček, H. Garcia, J. Čejka, Catal. Sci. Technol. 2013, 3, 500.

24 W. F. Hoelderich, Stud. Surf. Sci. Catal. 1988, 41, 83.

25 H. VanBekkum, H.W.Kouwenhoven, Stud. Surf. Sci. Catal. 1988, 41, 45

26 M. J. Climent, A. Corma, S. Iborra, Chem. Rev. 2011, 111, 1072

27 E. Wimmer, S. Borghèse, A. Blanc, V. Bénéteau, P. Pale, Chem. Eur. J. 2017, 23, 1484.

28 A. Taguchi, F. Schüth, Microporous Mesoporous Matter. 2005, 77, 1.

29 D. Brunel, A. C Blanc, A. Galarneau, F. Fajula, Catal. Today 2002, 73, 139

30 C. T. Kresge, M. E. Leonowicz, W. J. Roth, J. C. Vartuli, "Synthetic Mesoporous Crystalline Material" US Patent 5,098,684, 1992 (assigned to ExxonMobil)

31 D. Zhao, J. Feng, Q. Huo, N. Melosh, G. H. Fredrickson, B. F. Chmelka, G. D. Stucky, Science 1998, 279, 548.

32 V. Pascanu, G. González Miera, A. K. Inge, B. Martín-Matute, J. Am. Chem. Soc. 2019, 141, 7223.

33 F. G. Cirujano, Chem CatChem 2019, 11, 5671.

34 J. Bour, A. M. Wright, X. He, M. Dinca, Chem Sci. 2020, 11, 1728.

35 I. Nath, J. Chakraborty, F. Verpoort, Chem Soc. Rev. 2016, 45, 4127.

36 H. Li, M. Eddaoudi, M. O'Keeffe, O. M. Yaghi, Nature 1999, 402, 276.

37 G. Ferey, C. Mellot-Draznieks, C. Serre, F. Millange, J. Dutour, S. Surble, I. Margiolaki, Science 2005, 309, 2040.

38 J. H. Cavka, S. Jakobsen, U. Olsbye, N. Guillou, C. Lamberti, S. Bordiga, K. P. Lillerud, J. Am. Chem. Soc. 2008, 130, 13850.

39 [39] H. Furukawa, F. Gandara, Y.-B. Zhang, J. Jiang, W. L. Queen, M. R. Hudson, O. M. Yaghi, J. Am. Chem. Soc. 2014, 136, 4369-4381.

40 [40] N. L. Rosi, J. Kim, M. Eddaoudi, B. Chen, M. O'Keeffe, O. M. Yaghi, J. Am. Chem. Soc. 2005, 127, 1504-1518.

41 N. M. Padial, E. Quartapelle-Procopio, C. Montoro, E. LopezMaya, J. E. Oltra, V. Colombo, A. Maspero, N. Masciocchi, S. Galli, I. Senkovska, S. Kaskel, E. Barea, J. A. R. Navarro, Angew. Chem. Int. Ed. 2013, 52, 1.

42 F. G. Cirujano, F. X. Llabrés i Xamena, J. Phys. Chem. Lett. 2020, 11, 4879.

43 J. Hajeka, M. Vandichel, B. V. de Voorde, B. Bueken, D. De Vos, M. Waroquier, V. Van Speybroeck, J. Catal. 2015, 331, 1.

44 C. Caratelli, J. Hajek, F. G. Cirujano, M. Waroquier, F. X. Llabres i Xamena, V. Van Speybroeck, J. Catal. 2017, 352, 401

45 P. Tian, Y. Wei, M. Ye, Z. Liu, ACS Catal. 2015, 5, 1922.

46 I. Yarulina, A. D. Chowdhury, F. Meirer, B. M. Weckhuysen, J. Gascon, Nature Catal. 2018, 1, 398.
47 D. Yang, C. A. Gaggioli, D. Ray, M. Babucci, L. Gagliardi, B. C. Gates, J. Am. Chem. Soc. 2020, 142, 8044.

48 E. Plessers, G. Fu, C. Tan, D. E. De Vos, M. Roeffaers, Catalysts 2016, 6, 104.

49 D. Mei, J. A. Lercher, J. Phys. Chem. C 2019, 123, 25255.

50 F. G. Cirujano, F. X. Llabres i Xamena, A. Corma, Chem. Eng Sci. 2015, 124, 52.

51 G. Fu, F. G. Cirujano, A. Krajnc, G. Mali, M. Henrion, S. Smolders, D. De Vos, Catal. Sci. Technol. 2020, 10, 4002.

52 N. Lucas, G. Kokate, A. Nagpure, S. Chilukuri, Microporous Mesoporous Mater. 2013, 181, 38.

53 I. Anastasiou, N. Van Velthoven, E. Tomarelli, A. Lombi, D. Lanari, P. Liu, S. Bals, D. E. De Vos, L. Vaccaro, ChemSusChem 2020, 13, 2786

54 A. H. Valekar, K.-H. Cho, S. K. Chitale, D.-Y. Hong, G.-Y. Cha, U.H. Lee, Green Chem. 2016, 18, 4542.

55 L. Bui, H. Luo, W. R. Gunther, Y. Roman Leshkov, Angew. Chem. Int. Ed. 2013, 52, 8022.

56 J. Wang, S. Jaenicke, G.-K. Chuah, RSC Adv. 2014, 4, 13481

57 M. M. Kaid, A. Gebreil, S. A. El-Hakam, A. I. Ahmed, A. A. Ibrahim, RSC Adv. 2020, 10, 15586.

58 S. H. Doan, V. H. H. Nguyen, T. H.... Nguyen, P. H. Pham, N. N. Nguyen, A.N. Q. Phan, T. N. Tu, N. T. S. Phan, RSC Adv. 2018, 8,10736.

59 H. D. Park, M. Dinca, Y. Roman-Leshkov, ACS Cent. Sci. 2017, 3, 444.

60 H. D. Park, M. Dinca, Y. Roman-Leshkov, J. Am. Chem. Soc. 2018, 140, 10669.

61 F. G. Cirujano, F. X. Llabres I Xamena, A. Corma, Catal. Today 2015, 257, 213

62 S. N. Coman, D. C. Rafu, V. I. Parvulescu, Z. Sobalik, D. E. De Vos, P. A. Jacobs, Stud. Surf. Sci. Catal. 2004, 154, 2696.

63 S. N. Coma, V. I. Parvulescu, M. De Bruyn, D. E. De Vos, P. A. Jacobs, J. Catal. 2002, 206, 218.

64 M. De bruyn, S. Coman, R. Bota, Vasile I. Parvulescu, D. De Vos, P. A. Jacobs, Angew. Chem. Int. Ed. 2003, 42, 5333.

65 F. G. Cirujano, I. Luz, M. Soukri, C. Van Goethem, I. F.J. Vankelecom, M. Lail, D.E. De Vos, Angew. Chem. Int. Ed. 2017, 56, 13302

66 H.-H. Mautschke, F. Drache, I. Senkovska, S. Kaskel, F. X. Llabrés i Xamena, Catal. Sci. Technol. 2018, 8, 3610.

67 J. Luiz F. Monteiro, C. O. Veloso, Top. Catal. 2004, 27, 169.

68 F. Neaţu, S. Coman, V. I. Pârvulescu, G. Poncelet, D. De Vos, P. Jacobs, Top. Catal. 2009, 52, 1292

69 F. G. Cirujano, F. X. Llabrés I Xamena, Dalton Trans. 2012, 41, 4249.

70 B. R. Reiner, A. A. Kassie, C. R. Wade, Dalton Trans. 2019, 48, 9588.

71 P. Mäki-Arvela, N. Kumara, V. Nieminen, R. Sjöholm, T. Salmi, D. Y. Murzin, J. Catal. 2004, 225, 155.

72 F. Vermoortele, M. Vandichel, B. Van de Voorde, R. Ameloot, M. Waroquier, V. Van Speybroeck, D. E. de Vos, Angew. Chem. Int. Ed. 2012, 51, 4887.

73 E. Vitaku, D. T. Smith, J. T. Njardarson, J. Med. Chem. 2014, 57, 10257.

74 J. Zhang, L. Wang, Y. Shao, Y. Wang, B. C. Gates, F.-S. Xiao Angew. Chem. 2017, 129, 9879.

75 F. G. Cirujano, A. Leyva-Pérez, A. Corma, F. X. Llabrés i Xamena, Chem CatChem 2013, 5, 538.

76 F. G. Cirujano, E Lopez-Maya, M. Rodriguez-Albelo, E. Barea, J. A. R. Navarro, D. E. De Vos, ChemCatChem. 2017, 9 4019.

77 F. G. Cirujano, N. Martín, G. Fu, C. Jia, D. De Vos, Catal. Sci. Technol. 2020, 10, 1796.

78 A. I. Carrillo, P. Llanes, M. A. Pericàs, React. Chem. Eng. 2018, 3, 714

79 E. López-Maya, C. Montoro, V. Colombo, E. Barea, J. A. R. Navarro, Adv. Funt. Mater. 2014, 24, 6130. 
80 C. Montoro, P. Ocon, F. Zamora, J. A. R. Navarro, Chem. Eur. J. 2016, 22, 1646.

81 J. V. Alegre-Requena, E. Marqués-López, R. P. Herrera, D. Díaz, CrystEngComm 2016, 18, 3985.

82 F. G. Cirujano, E. López-Maya, J. A. R. Navarro, D. E. De Vos, Top. Catal. 2018, 61, 1414

83 B. R. Reiner, N. T. Mucha, A. Rothstein, J. S. Temme, P. Duan, K. Schmidt-Rohr, B. M. Foxman, C. R. Wade, Inorg Chem. 2018, 57, 5, 2663.

84 Q. Chen, L. Lv, M. Yu, Y. Shi, Y. Li, G. Pang, C. Cao, RSC Adv. 2013, 3, 18359.

85 A. Arcadi, G. Bianchi, F. Marinelli, Synthesis 2004, 4, 610.

86 E. Pérez-Mayoral, Z. Musilová, B. Gil, B. Marszalek, M. Položij, P. Nachtigall, J. Čejka, Dalton Trans. 2012, 41, 4036.

87 N. Martin, M. Dusselier, D. E. De Vos, F. G. Cirujano, ACS Catal. 2019, 9, 44.

88 H. V. Dang, H. T. B. Le, L. T. B. Tran, H. Q. Ha, H. V. Lea, N. T. S. Phan, RSC Adv. 2018, 8, 31455.

89 C. B. Tran, T. A. To, Y. H. Vo, T. T. L. Do, Q. T. P. Nguyen, A. T. Nguyen, T, T. Nguyen, N. T. S. Phan, Chem. Select 2019, 4, 880.

90 V. L. Rechac, F. G. Cirujano, A. Corma, F. X. Llabrés I Xamena, Eur. J. Inorg. Chem. 2016, 4512.

91 M. Abdollahi-Alibeik, M. Pouriayevali, Reac. Kinet. Mech. Catal. 2011, 104, 235.

92 A. Olmos, S. Rigolet, B. Louis, P. Pale, J. Phys. Chem. C 2012, 116, 13661.

93 K. De, S. Maity, P. Ghosh, C. Mukhopadhyay, Appl. Organometallic Chem. 2019, 33, n/a.

94 P. Gholamzadeh, G. M. Ziarani, A. Badiei, Z. Bahrami, Eur. J. Chem. 2012, 3, 279.

95 N. Linares, F. G. Cirujano, D. E. De Vos, J. Garcia-Martinez, Chem. Commun. 2019, 55, 12869.

96 F. G. Cirujano, M. Stalpaert, D. E. De Vos, Green Chem. 2018, 20, 2481.

97 P. Rubio-Marqués, M. A. Rivero-Crespo, A. Leyva-Pérez, A. Corma, J. Am. Chem. Soc. 2015, 137, 11832.

98 F. G. Cirujano, P. Leo, J. Vercammen, S. Smolders, G. Orcajo, D. E. De Vos, Adv. Synth. Catal. 2018, 360, 3872.

99 [99] L. Djakovitch and P. Rouge, J. Molec. Catal. A, 2007 273, 230 .

100 N. Van Velthoven, M. Henrion, J. Dallenes, A. Krajnc, A. L. Bugaev, P. Liu, S. Bals, A. V. Soldatov, G. Mali, D. E. De Vos, ACS Catal. 2020, 10, 5077.

101 I. Luz, F. X. Llabrés i Xamena, A. Corma, J. Catal. 2012, 285, 285.

102 G. H. Dang, D. T. Le, T. Truong, N. T. S. Phan, J. Molec. Catal. A 2015, 400, 162.

103 S. Rostamnia, A. Morsali, RSC Adv. 2014, 4, 10514. 